\title{
A Molecular Clutch between the Actin Flow and N-Cadherin Adhesions Drives Growth Cone Migration
}

\author{
Lucie Bard, ${ }^{1}$ Cécile Boscher, ${ }^{2}$ Mireille Lambert, ${ }^{2}$ René-Marc Mège, ${ }^{2}$ Daniel Choquet, ${ }^{1}$ and Olivier Thoumine ${ }^{1}$ \\ ${ }^{1}$ Unité Mixte de Recherche 5091, Centre National de la Recherche Scientifique, Institut François Magendie, Université Bordeaux 2, 33077 Bordeaux, France, \\ and ${ }^{2}$ Inserm U839, Institut du Fer à Moulin, Université Pierre et Marie Curie, 75005 Paris, France
}

The adhesion molecule N-cadherin plays important roles in the development of the nervous system, in particular by stimulating axon outgrowth, but the molecular mechanisms underlying this effect are mostly unknown. One possibility, the so-called "molecular clutch" model, could involve a direct mechanical linkage between $\mathrm{N}$-cadherin adhesion at the membrane and intracellular actin-based motility within neuronal growth cones. Using live imaging of primary rat hippocampal neurons plated on N-cadherin-coated substrates and optical trapping of $\mathrm{N}$-cadherin-coated microspheres, we demonstrate here a strong correlation between growth cone velocity and the mechanical coupling between ligand-bound $\mathrm{N}$-cadherin receptors and the retrograde actin flow. This relationship holds by varying ligand density and expressing mutated $\mathrm{N}$-cadherin receptors or small interfering RNAs to perturb binding to catenins. By restraining microsphere motion using optical tweezers or a microneedle, we further show slippage of cadherin-cytoskeleton bonds at low forces, and, at higher forces, local actin accumulation, which strengthens nascent $\mathrm{N}$-cadherin contacts. Together, these data support a direct transmission of actin-based traction forces to $\mathrm{N}$-cadherin adhesions, through catenin partners, driving growth cone advance and neurite extension.

Key words: axon elongation; $\mathrm{N}$-cadherin-Fc fusion protein; catenins; optical tweezers; single particle tracking; micromanipulation

\section{Introduction}

Growth cones are motile structures at the distal extremity of axons responsible for pathfinding and neurite extension during nervous system development and repair. Growth cone motility relies on a dynamic regulation of the actin network, with polymerization occurring at the leading edge, depolymerization in the central region, and the activity of myosins pulling on lamellipodial actin filaments (Lin et al., 1996; Mallavarapu and Mitchison, 1999; Diefenbach et al., 2002). This results altogether in a continuous retrograde flow of actin.

Growth cones adhere to the extracellular matrix and adjacent cells through specific adhesion receptors, i.e., integrins, Ig cell adhesion molecules (IgCAMs), and cadherins. An important question is how growth cone progression on adhesive substrates is coupled to actin motility. A prevalent hypothesis, the "molecular clutch" mechanism, is that the mechanical coupling between ligand-bound adhesion receptors and the actin flow allows traction forces to be transmitted to the substrate, resulting in local diminution of the retrograde flow and forward progression (Mitchison and Kirschner, 1988; Suter and Forscher, 1998). In the case of Aplysia growth cones interacting through ApCAM

\footnotetext{
Received Dec. 1, 2007; revised March 28, 2008; accepted April 20, 2008.

This work was supported by the French Ministry of Research, Centre National de la Recherche Scientifique, Conseil Régional Aquitaine, Association Française contre les Myopathies, Association pour la Recherche sur le Cancer, and Inserm. We thankC. Dequidt for preliminary experiments, C. Breillat for the production of SynCAM-Fc, P. Gonzales for coverslip preparation, D. Bouchet and B. Tessier for neuronal cultures, V. Marthiens for the production of cad11-Fc, and J. Falk, G. Giannone, D. Perrais, and C. Sarrailh for critical reading of this manuscript.

Correspondence should be addressed to Olivier Thoumine at the above address. E-mail: olivier.thoumine@pcs.u-bordeaux2.fr.

DOI:10.1523/JNEUROSCI.5331-07.2008

Copyright $\odot 2008$ Society for Neuroscience $\quad$ 0270-6474/08/285879-12\$15.00/0
}

[the homolog of vertebrate neural cell adhesion molecule (NCAM)], such substrate-cytoskeletal coupling is indeed accompanied by protrusion of the microtubule-rich central domain toward stiff contacts and forward expansion of the actinrich lamellipodium (Lin and Forscher, 1995; Suter et al., 1998). However, the relationship between the actual translocation of growth cones leading to axonal elongation and the degree of receptor coupling to the actin flow has not been demonstrated.

The adhesion receptor $\mathrm{N}$-cadherin $(\mathrm{Ncad})$ plays a role in a variety of processes in the CNS of vertebrates, including cell positioning (Kadowaki et al., 2007), axon outgrowth (Riehl et al., 1996), fasciculation and dendritic branching (Yu and Malenka, 2003; Bekirov et al., 2007), synaptogenesis (Benson and Tanaka, 1998), and synaptic plasticity (Bozdagi et al., 2000; Togashi et al., 2002; Okamura et al., 2004). The effect of N-cadherin in promoting axonal growth can be mimicked in cell culture models (Matsunaga et al., 1988; Lemmon et al., 1992; Saffell et al., 1997; Kamiguchi and Yoshihara, 2001), but the underlying molecular mechanisms remain unclear. In particular, whether a clutch process exists for $\mathrm{N}$-cadherin-mediated growth cone locomotion and which molecular partners it may involve is still unknown. Here, using primary neurons interacting with $\mathrm{N}$-cadherin-coated substrates together with live imaging and optical manipulation, we show that the mechanical coupling between $\mathrm{N}$-cadherin receptors and the actin flow through catenins is a major determinant of growth cone motility and neurite extension.

\section{Materials and Methods}

Reagents. Ncad-Fc and cadherin 11 (cad11)-Fc were produced at 200 $\mu \mathrm{g} / \mathrm{ml}$ as described previously (Lambert et al., 2000; Marthiens et al., 2005). Synaptic CAM (SynCAM)-Fc was constructed from a SynCAM 
plasmid given by T. Biederer (Yale University, New Haven, CT) (Biederer et al., 2002) and purified similarly (Breillat et al., 2007). GC4 monoclonal antibody against chicken $\mathrm{N}$-cadherin, globulin free BSA, cytochalasin D, and other chemicals were purchased from Sigma.

Constructs. Plasmids coding for C-terminal green fluorescent protein (GFP)-tagged chicken wild-type $\mathrm{N}$-cadherin (NcadWT) and N-cadherin deleted of the 35 aa $\mathrm{C}$-terminal $\beta$-catenin binding region ( $\mathrm{Ncad} \Delta \beta \mathrm{cat}$ ) were described previously (Thoumine et al., 2006). Wild-type chicken $\mathrm{N}$-cadherin fused in $\mathrm{C}$ terminus with DsRed tandem dimer (NcadDsRed) has been described previously (Lambert et al., 2007). N-terminal myc-tagged Xenopus N-cadherin lacking the extracellular domain (Ncad $\Delta$ extra) was a kind gift from C. Holt (Riehl et al., 1996). Mouse $\mathrm{N}$-cadherin with triple alanine mutation in the juxtamembrane domain known to abolish binding to p120 (NcadAAA) tagged with yellow fluorescent protein (YFP) in the $\mathrm{C}$ terminal was a kind gift from K. G. Green (Northwestern University, Chicago, IL) (Chen et al., 2003). Actin-GFP was a gift from A. Matus (Friedrich Miescher Institute, Basel, Switzerland) (Fischer et al., 1998). pEGFP-N1 was from Clontech. To knock down $\alpha$-catenin expression, we used small interfering RNA (siRNA) duplexes (Proligo) targeting the $\alpha$ E-catenin sequence $5^{\prime}$ AAAGACGTGGATGGGCTGGAT-3 [RNA interference (RNAi)]. Another duplex, 5'-AAGAAGGCCCATGTTTTGGCT-3', also matching $\alpha$ E-catenin mRNA, but which did not disturb $\alpha$ E-catenin protein expression, was used as a control (RNActr).

Substrate coating. Glass coverslips $(15 \mathrm{~mm})$ were cleaned overnight with $6 \mathrm{M}$ nitric acid, rinsed with deionized water, and autoclaved. Coverslips were incubated for $2 \mathrm{~h}$ at $37^{\circ} \mathrm{C}$ with $1 \mathrm{mg} / \mathrm{ml}$ polylysine, then overnight at $4^{\circ} \mathrm{C}$ with $4 \mu \mathrm{g}$ of goat anti-mouse Fc (Jackson ImmunoResearch) in $100 \mu \mathrm{l}$ of $0.2 \mathrm{~m}$ borate buffer, $\mathrm{pH} 8.5$, and finally for $3 \mathrm{~h}$ at room temperature with $0.03-3 \mu \mathrm{g}$ of Ncad-Fc or $3 \mu \mathrm{g}$ of mouse Fc. Alternatively, substrates were coated with goat anti-human $\mathrm{Fc}$ and then incubated with $3 \mu \mathrm{g}$ of cad11-Fc or $3 \mu \mathrm{g}$ of SynCAM-Fc. In control experiments, substrates were coated for $2 \mathrm{~h}$ with polylysine then incubated overnight at $4^{\circ} \mathrm{C}$ with $50 \mu \mathrm{g} / \mathrm{ml}$ laminin (BD Biosciences). For optical tweezers experiments, coverslips were treated with polylysine alone.

Cell culture and transfection. Hippocampal neurons from embryonic day 18 rat embryos were plated on these substrates at a density of 10,000 cells $/ \mathrm{cm}^{2}$ in Modified Eagle's Medium (MEM) containing 10\% horse serum (Invitrogen) for $3 \mathrm{~h}$, then turned onto a layer of glial cells and cultured in Neurobasal medium supplemented with B27 (Goslin et al., 1991). Cells were transfected using Effectene (Qiagen) or calcium phosphate (Thoumine et al., 2006) with similar results. Cells were manipulated $30-40 \mathrm{~h}$ after transfection. In some experiments, $4 \mathrm{~mm}$ EGTA, 1:50 GC4 antibody, $1 \mu \mathrm{M}$ cytochalasin D, or 1:1000 DMSO were added to the culture or observation media. $\alpha$-Catenin downregulation by RNA interference was performed by cotransfection of GFP vector as a reporter with RNA duplexes, using calcium phosphate or Lipofectamine 2000 (Invitrogen): $3 \mu \mathrm{l}$ of reagent, $0.6 \mu \mathrm{g}$ of vector, and $0.9 \mu \mathrm{g}$ of RNAi or RNActr were used to transfect one $15 \mathrm{~mm}$ glass coverslip. Neurons were incubated for $1 \mathrm{~h}$ with this solution in MEM supplemented with 2\% B27, 2 mM glutamine, 1 mm Na-pyruvate, and 1 m HEPES (Eugene et al., 2007). Fortyeight hours after transfection, siRNA efficiency was checked by Western blot and immunostaining.

Quantification of growth cone velocity and neurite arborization. Cells at $1-2 \mathrm{~d}$ in vitro (DIV) were mounted in Neurobasal medium containing 20 mM HEPES for live observation on an inverted microscope (Olympus IX50) using a $40 \times, 1.3$ numerical aperture (NA) objective and differential interference contrast (DIC) illumination. Images were acquired every $10 \mathrm{~s}$ for 30 min using a CCD camera (HQ CoolSnap; Roper Scientific) driven by the MetaMorph software (Universal Imaging). Three regions were recorded simultaneously by scanning the sample with the motorized stage (MarzHauser). Temperature was maintained at $37^{\circ} \mathrm{C}$ with an air blower (World Precision Instruments) and an objective heater (Bioptechs). The centroid coordinates of individual growth cones, as well as the number and length of neurites from neuronal cultures fixed with $4 \%$ paraformaldehyde, were analyzed using NIH ImageJ.

Microsphere preparation. Five microliters of $1 \mu \mathrm{m}$ sulfate latex microspheres (Polysciences; $4.5 \times 10^{7}$ particles/ $\mu \mathrm{l}$ ) were incubated overnight at $4^{\circ} \mathrm{C}$ with $10 \mu \mathrm{g}$ of goat anti-Fc antibody (Jackson ImmunoResearch) in
$50 \mu \mathrm{l}$ of $0.2 \mathrm{~m}$ borate buffer, $\mathrm{pH}$ 8.5. Microspheres were rinsed in borate buffer containing $0.3 \% \mathrm{BSA}$, and $20 \mu \mathrm{l}$ of the suspension was incubated at room temperature for $3 \mathrm{~h}$ with $10 \mu \mathrm{g}$ of cad11-Fc, SynCAM-Fc, or Fc, or $0.1-10 \mu \mathrm{g}$ of Ncad-Fc. Beads were rinsed again three times, resuspended in $100 \mu \mathrm{l}$, and kept on ice during the experiments. The same protocol was used to coat $5 \mu \mathrm{l}$ of $4 \mu \mathrm{m}$ magnetic microspheres (density, $\rho_{m}=1.3 \mathrm{mg} / \mathrm{ml} ; 4 \times 10^{5}$ particles $/ \mu \mathrm{l}$; Dynal), or 2 and $4 \mu \mathrm{m}$ sulfate microspheres $\left(2.7 \times 10^{6}\right.$ particles $/ \mu \mathrm{l}$; Interfacial Dynamics $)$ with $2 \mu \mathrm{g}$ $\mathrm{Ncad}-\mathrm{Fc}$ for bead adhesion and micromanipulation experiments, respectively.

Bead adhesion assays. Coverslips containing neurons at 2 DIV were placed in a 12 -well plate using $1 \mathrm{ml}$ of culture medium supplemented with $1 \%$ BSA per coverslip and incubated at $37^{\circ} \mathrm{C}$ with $1 \mu \mathrm{l}$ of bead suspension. After $30 \mathrm{~min}$, nonadherent beads were rinsed away using an aspiration flow rate of $1 \mathrm{ml} / \mathrm{s}$. This produces a Stokes force of $6 \pi \eta a v$, where $\eta$ is the medium viscosity $\left(10^{-3} \mathrm{~kg} \cdot \mathrm{m}^{-1} \cdot 5^{-1}\right), a$ is the radius of the bead, and $v$ the fluid velocity $(\sim 1 \mathrm{~cm} / \mathrm{s})$. In the case of magnetic beads, coverslips were turned upside down and the 12-well plate was centrifuged at a relative centrifugal force (RCF) of $1730 \times g$ for $15 \mathrm{~min}$ to pull on adherent beads. The force applied was then $(4 / 3) \pi a^{3}\left(\rho_{m}-\rho_{l}\right)$ RCF, where $\rho_{l}(1 \mathrm{mg} / \mathrm{ml})$ is the fluid density. Cells were then fixed in $4 \%$ paraformaldehyde $/ 4 \%$ sucrose in PBS, mounted on microscope slides, and observed using a $40 \times$ objective. In the case of transfected cells, immunocytochemistry was performed as described previously (Thoumine et al., 2006) using 1:1000 anti-GFP rabbit (Invitrogen) or chicken (Millipore) serum, 1:50 monoclonal anti-rat N-cadherin (Transduction Laboratories), 1:500 polyclonal anti-myc (Upstate), or $1: 75$ anti- $\alpha$ E-catenin rabbit (Epitomics) or mouse (Santa Cruz Biotechnology) serum as primary antibodies, and 1:1000 Alexa-568-conjugated secondary antibodies (Invitrogen). Ratios of intensity of $\alpha$-catenin and control stainings from GFP-expressing neurons were assessed using ImageJ software.

Optical tweezer experiments. An inverted microscope was fed through its epifluorescence port by an Nd:YAG laser beam (Compass; Coherent). Trapping was achieved with a laser power of $100 \mathrm{~mW}$ at the back plane of a $100 \times, 1.40$ NA objective. Microspheres captured using a motorized stage (MarzHauser) were maintained at the periphery of growth cones for $2 \mathrm{~s}$, then their movement in DIC illumination was recorded for $2 \mathrm{~min}$ at $10 \mathrm{~Hz}$. Trajectories were tracked using MetaMorph, and the mean squared displacement over time was computed using a homemade algorithm (Thoumine et al., 2005). Alternatively, the trap was applied continuously for $2 \mathrm{~min}$. The trap stiffness $k$ was estimated by measuring the position fluctuations $\Delta x$ of captured beads at $40 \mathrm{~Hz}$. Using the equipartition theorem $\left.k<\Delta x^{2}\right\rangle=k_{B} T$, where $k_{B} T$ is the thermal energy, we found $k=4.4 \mathrm{pN} / \mu \mathrm{m}$. We checked for linearity between laser power and trap stiffness.

Micromanipulation. Microneedles were pulled from 1-mm-diameter glass rods (Clark Electromedical) using a micropipette puller (Sutter Instruments) and coated with $1 \%$ BSA. Microneedle stiffness estimated from the geometric profile of the tip and the knowledge of the glass Young's modulus was in the range of $1 \mathrm{nN} / \mu \mathrm{m}$. Coarse positioning was achieved using a $20 \times$ objective and a three-axes motor-driven micromanipulator (Eppendorf). Fine positioning was performed using a piezoelectric device (Burleigh) and a $100 \times$ objective. Growth cones were oriented with respect to a fixed microneedle using a manual rotation plate (Thorlabs). Ncad-Fc-coated beads $(4 \mu \mathrm{m})$ were maintained on growth cones for $10 \mathrm{~s}$, then left alone or immediately restrained with the microneedle and pulled forward at a velocity of $\sim 1 \mu \mathrm{m} / \mathrm{min}$. Alternating transmission and GFP fluorescence images were taken at $10 \mathrm{~Hz}$ for 10 min.

Statistics. For the quantification of neurite length, growth cone velocity, and coupling index, data from three to five separate experiments were pooled and expressed as mean \pm SEM. The number of cells or beads examined in each condition is indicated in italics on the graphs in the Figures. All coating conditions or transfections were run in parallel on the same batches of neurons and compared by one-way ANOVA using GraphPad Prism. Individual conditions were compared with controls (Fc or GFP, respectively) by Dunnett's test, or two by two using Tukey's test. Correlations were calculated using a linear fit and Pearson's test. 

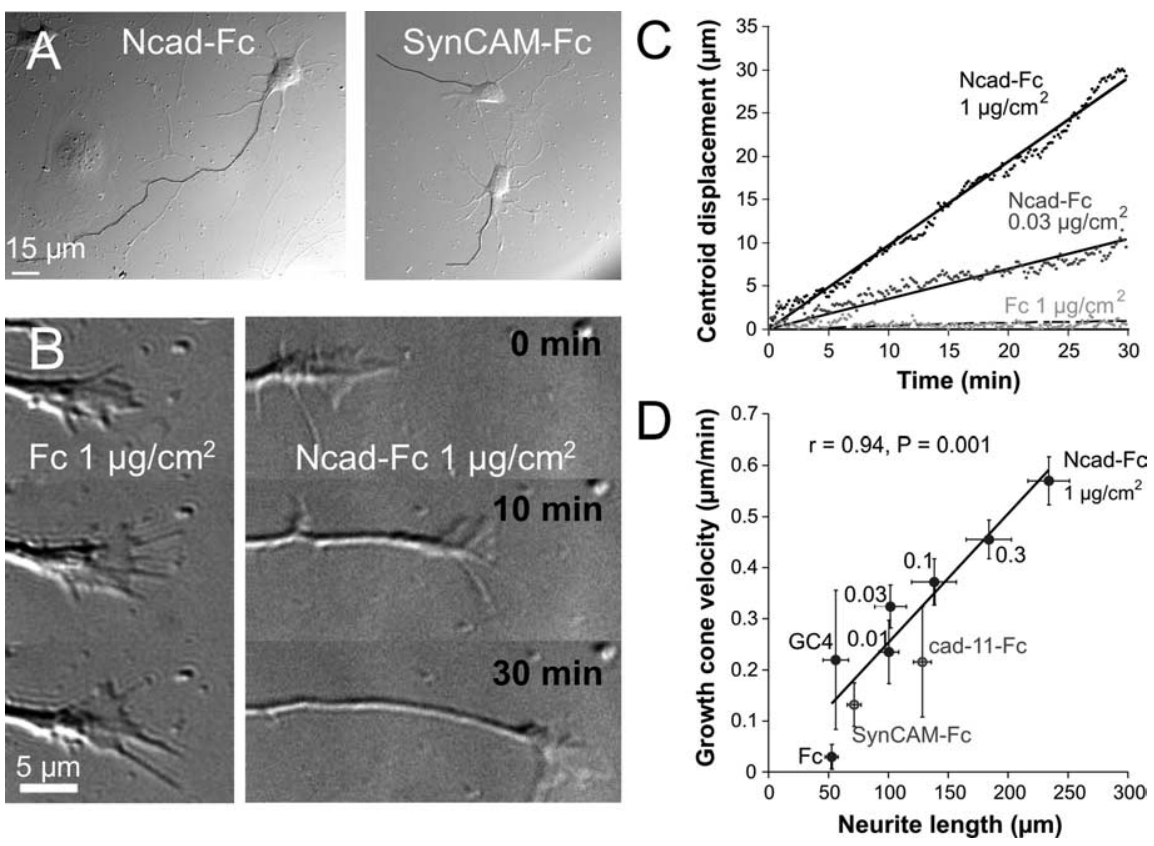

Figure 1. Effect of Ncad-Fc density on neurite length and growth cone velocity. Primary neurons were plated on glass coverslips coated with various dilutions of Ncad-Fc, cad11-Fc, synCAM-Fc, or Fc and observed 2 d later. $\boldsymbol{A}$, Images for Ncad-Fc and synCAM-Fc substrates (coating density, $1 \mu \mathrm{g} / \mathrm{cm}^{2}$ ), where the longest neurite is outlined. $\boldsymbol{B}$, Time-lapse images of growth cones moving on Ncad-Fc or Fc substrates. We specifically selected growth cones from the longest neurites. $\boldsymbol{C}$, The positions of individual growth cone centroids were tracked, and their displacement was plotted over time. $\boldsymbol{D}$, Correlation between growth cone velocity and length of the longest neurite, including all conditions. The average neurite length was calculated from 10-54 cells, and the average velocity was obtained from 11-64 individual growth cones per condition. SynCAM and Cad-11 (open circles) are not taken into account for the correlation.

\section{Results}

$\mathrm{N}$-cadherin selectively stimulates neurite extension and growth cone migration

We first developed an experimental system supporting $\mathrm{N}$-cadherin-specific neuritic growth. We used rat embryonic hippocampal neurons plated on glass coverslips coated with purified $\mathrm{N}$-cadherin-Fc. Ncad-Fc induced a more developed neuritic network when compared with substrates coated with other adhesion proteins cad11-Fc or SynCAM-Fc, or Fc alone (Fig. 1A). This neuritogenic effect of $\mathrm{N}$-cadherin was similar to that reported previously for other neurons (Lemmon et al., 1992; Saffell et al., 1997; Kamiguchi and Yoshihara, 2001). The number of neurites per cell (data not shown) and the length of the longest neurite, most likely the axon, increased with Ncad-Fc coating density (Fig. 1D). We also characterized growth cone locomotion using time-lapse microscopy (Fig. 1 B; supplemental Videos 1, 2, available at www.jneurosci.org as supplemental material). The displacement of growth cone centroids increased in a steady manner over time, without pauses, allowing the calculation of a long-term velocity (Fig. 1C). Growth cone velocity increased with Ncad-Fc coating density and sharply correlated with neurite length (Fig. $1 D$ ), indicating that the neuritogenic effect of $\mathrm{N}$-cadherin is driven by a stimulation of growth cone migration. The linear relationship agrees with the concept that growth cones extend neurites by pulling on them, the velocity of growth cones being translated into a constant rate of neurite extension (Lamoureux et al., 2002). Those effects were specific of $\mathrm{N}$-cadherin adhesion because addition of the calcium chelator EGTA or the GC4 antibody to block N-cadherin homophilic binding drastically reduced growth cone advance and neurite extension (Fig. 1D).
$\mathrm{N}$-cadherin anchorage to the actin flow correlates with growth cone velocity Next, we characterized the physical coupling between $\mathrm{N}$-cadherin and the underlying actin flow using Ncad-Fc-coated microspheres manipulated by optical tweezers. Neurons were plated on polylysine to avoid mobilization of endogenous $\mathrm{N}$-cadherin receptors at the basal surface. Microspheres were placed on growth cones for $2 \mathrm{~s}$, then either the optical trap was released and bead trajectories were followed for $2 \mathrm{~min}$, or the trap was applied continuously and the latency for beads to escape was quantified (Fig. 2, top). One hundred percent of beads coated with $1 \mu \mathrm{g} / \mathrm{cm}^{2}$ Ncad-Fc density stayed adherent to the dorsal growth cone surface $(n=40)$, and that fraction was reduced to $32 \%$ in the presence of EGTA $(n=26)$ or $12 \%$ using function-blocking antibodies to $\mathrm{N}$-cadherin $(n=24)$, indicating adhesion specificity. Microspheres coated with high Ncad-Fc density $\left(0.3\right.$ and $\left.1 \mu \mathrm{g} / \mathrm{cm}^{2}\right)$ showed directed retrograde movement with minimal lateral diffusion (Fig. 2A; supplemental Video 3, available at www. jneurosci.org as supplemental material) and could escape the optical trap in a few seconds (Fig. 2D). At intermediate Ncad-Fc densities $\left(0.1\right.$ and $\left.0.03 \mu \mathrm{g} / \mathrm{cm}^{2}\right)$, bead trajectories were more irregular and characterized by a higher degree of lateral mobility (Fig. 2B). Beads also showed a longer latency period before escaping the trap (Fig. 2E). Microspheres coated with minimal Ncad-Fc densities $\left(0.01 \mu \mathrm{g} / \mathrm{cm}^{2}\right)$ or Fc alone adhered poorly and showed essentially Brownian motion (Fig. 2C; supplemental Video 4, available at www.jneurosci.org as supplemental material). They also stayed for minutes in the continuously applied trap (Fig. $2 F$ ) and could easily be dragged along the neuronal surface (data not shown). For each trajectory, the mean squared displacement over time $(t)$ was fitted by the diffusion/ flow equation $4 D t+V^{2} t^{2}$ (Fig. $2 G$ ), where $D$ and $V$ represent the diffusion coefficient and retrograde velocity of the bead, respectively (Kucik et al., 1991). The velocity of Ncad-Fc-coated beads ( $\sim 5 \mu \mathrm{m} / \mathrm{min}$ ), close to the retrograde velocity of fluorescently labeled actin measured in DRG neurons (Diefenbach et al., 2002), was independent of Ncad-Fc concentration and dramatically reduced by the addition of cytochalasin $\mathrm{D}$, which abolishes actin dynamics (Table 1). Thus, the parameter $V$ likely reflects the actual speed of the actin retrograde flow. In contrast, the diffusion coefficient $D$ decreased as Ncad-Fc density was raised, reflecting higher coupling (Table 1). We also measured the fraction of beads escaping the trap before $1 \mathrm{~min}\left(P_{\mathrm{e}}\right)$, which increased smoothly with Ncad-Fc concentration and dropped to zero in the presence of cytochalasin D (Table 1).

We pooled the effects on bead diffusion, velocity, and escape into a single robust parameter called a coupling index, and defined as $P_{\mathrm{e}} V \log \left(D_{0} / D\right)$ (in micrometers per minute). The logarithmic function stems from the fact that the diffusion coefficient of membrane proteins often spans several orders of magnitude (Kucik et al., 1999; Thoumine et al., 2005) and uses a reference diffusion coefficient $D_{0}$, the one obtained for Fc-coated beads 
$\left(0.03 \mu \mathrm{m}^{2} / \mathrm{s}\right)$. After checking by immunofluorescence that the amounts of Ncad-Fc adsorbed on microspheres and glass coverslips increased similarly with coating concentration (supplemental Fig. 1, available at www.jneurosci.org as supplemental material), we plotted the coupling index versus growth cone velocity (Fig. $2 H$ ). We observed a sharp correlation, demonstrating that the degree of $\mathrm{N}$-cadherin receptor anchoring to the retrograde actin flow is a good predictor of growth cone advance. The effect was specific of $\mathrm{N}$-cadherin because two other ligands, cadherin-11 and SynCAM, fell well outside the correlation line (Fig. $2 H$ ).

\section{Slippage of bonds between N-cadherin receptors and the actin flow at low forces} The fact that even at maximal Ncad-Fc coating density the velocity of growth cones $(\sim 1 \mu \mathrm{m} / \mathrm{min})$ remains much smaller than the speed of the actin flow $(5 \mu \mathrm{m} /$ min) implies some slippage between the moving actin network and N-cadherin receptors engaged in adhesive interactions at the basal surface. To investigate this process, we more closely examined the behavior of beads coated with medium Ncad-Fc densities (0.03 and $\left.0.1 \mu \mathrm{g} / \mathrm{cm}^{2}\right)$ maintained on growth cones with the optical trap applied continuously. We observed many breaking events in which beads started to move rearward for $0.3-0.6 \mu \mathrm{m}$, then occasionally snapped back into the trap center in $<200 \mathrm{~ms}$ (Fig. $3 A, B$; supplemental Video 5, available at www. jneurosci.org as supplemental material). Sixty-eight such events were recorded from 282 beads tested (breaking frequency, 0.24). The frequency of retrapping events was dramatically increased in the presence of cytochalasin D (7 events from 9 beads; frequency, 0.77 ) versus the control DMSO condition ( 2 events from 10 beads; frequency, 0.20 similar to untreated cells), indicating that this phenomenon reflects a transient linkage to the actin network. By multiplying the distance traveled from the trap center by the trap stiffness, we computed the corresponding breaking forces, on average $1.6 \pm 0.1 \mathrm{pN}(n=$ $68)$. The histogram showed a major peak centered at $1.2 \mathrm{pN}$, together with smaller secondary peaks at 2.5 and $4 \mathrm{pN}$ (Fig. 3C), supporting the notion that bead recapture corresponded to the breakage of individual or very few molecular bonds. Note that 1 $\mu \mathrm{g} / \mathrm{cm}^{2}$ Ncad-Fc beads escape readily (Fig. $3 B$ ) because the optical trap is not strong enough compared with the forces generated by the actin flow. We will show later an assay using a microneedle in which we can indeed restrain microspheres and demonstrate slippage at high Ncad-Fc coating density.

\section{Perturbing interactions between $\mathrm{N}$-cadherin receptors and catenins similarly affect neurite outgrowth and receptor-cytoskeletal coupling}

To investigate the molecular determinants underlying the anchorage of $\mathrm{N}$-cadherin to the actin flow, we first used an approach
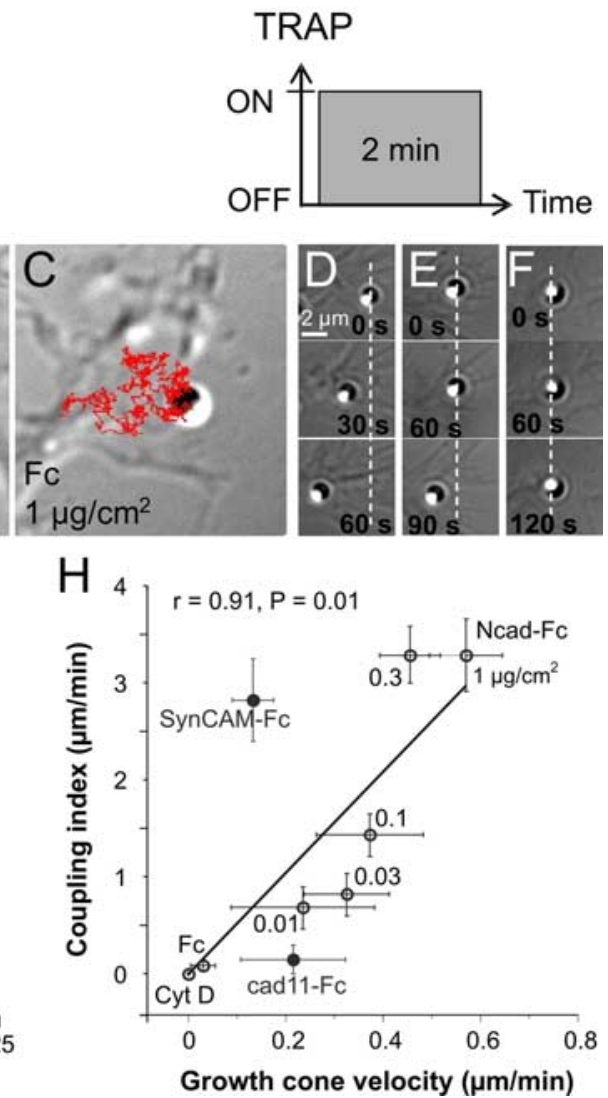

Figure 2. Relationship between receptor-cytoskeleton anchoring and growth cone velocity. $\boldsymbol{A}-\boldsymbol{F}$, Latex microspheres (1 $\mu \mathrm{m})$ coated with high Ncad-Fc density $(\boldsymbol{A}, \boldsymbol{D})$, medium Ncad-Fc density $(\boldsymbol{B}, \boldsymbol{E})$, or $\mathrm{Fc}$ alone $(\boldsymbol{C}, \boldsymbol{F})$ were either placed for $2 \mathrm{~s}$ at the periphery of growth cones using optical tweezers and then left alone for $2 \mathrm{~min}$ (top left diagram, $\boldsymbol{A}-\boldsymbol{C}$ ) or restrained by continuous 列 squared displacement from each trajectory was plotted over time $(t)$ and fitted by the equation $4 D t+V^{2} t^{2}$, where $D$ and $V$ are the diffusion coefficient and the mean velocity of the bead, respectively ( 3 individual examples are shown). $\chi^{2}$ values obtained with this two-parameter equation were substantially lower than for a single component equation, indicating a better fit (e.g., for the intermediate Ncad-Fc coating, $\chi^{2}=0.06$ for the double component, $\chi^{2}=2.1$ for flow only, and $\chi^{2}=3.3$ for diffusion alone). $\boldsymbol{H}$, Correlation between coupling index and growth cone velocity for the various Ncad-Fc dilutions. The average coupling index was calculated for a total of 10-38 individual beads per condition.

based on the expression of mutated $\mathrm{N}$-cadherin receptors. Neurons were transfected with either Ncad $\Delta$ extra (Riehl et al., 1996), $\mathrm{Ncad} \Delta \beta$ cat (Thoumine et al., 2006), NcadAAA (Chen et al., 2003), NcadWT, or GFP as a control. We showed previously that these receptors were expressed approximately twofold over endogenous N-cadherin and correctly addressed to the neuronal surface (Thoumine et al., 2006). We first characterized the effect of these constructs on neurite elongation for neurons plated on Ncad-Fc, and tested their specificity by comparing with cells grown on laminin. Transfection of NcadWT resulted in a slight (18\%), but not significant, diminution in neurite length when compared with GFP-positive cells, an effect that was also found for cells plated on laminin (Fig. 4). In contrast, neurons expressing Ncad $\Delta$ extra, Ncad $\Delta \beta$ cat, and NcadAAA all exhibited significantly shorter neurites compared with the GFP condition, with average reductions in length of 50, 30, and 45\%, respectively (Fig. 4). The effects of those mutants on neurite outgrowth were sometimes so strong that the neurons appeared to stay in a rather unpolarized stage, with little axon-dendrite differentiation (Bradke and Dotti, 1997; Lamoureux et al., 2002). The effect of $\mathrm{Ncad} \Delta$ extra was highly specific for Ncad-Fc because its expression did not alter axon growth on laminin (Fig. 4B). However, 
Table 1. Parameters characterizing microsphere motion as a function of $\mathrm{N}$-cadherin coating density

\begin{tabular}{lllllll}
\hline Ncad-Fc $\left(\mu \mathrm{g} / \mathrm{cm}^{2}\right)$ & $0(\mathrm{Fc})$ & 0.01 & 0.03 & 0.1 & 0.3 & $0.3+\mathrm{CytD}$ \\
\hline$D\left(10^{-2} \mu \mathrm{m}^{2} / \mathrm{s}\right)$ & $3.3 \pm 0.7$ & $1.6 \pm 0.3^{*}$ & $1.7 \pm 0.3^{*}$ & $1.2 \pm 0.2^{* *}$ & $0.9 \pm 0.1^{* *}$ & $0.9 \pm 0.1^{* *}$ \\
$V(\mu \mathrm{m} / \mathrm{min})$ & $1.9 \pm 0.5$ & $4.5 \pm 0.7^{*}$ & $4.8 \pm 0.7^{*}$ & $5.0 \pm 0.3^{* *}$ & $5.1 \pm 0.3^{* *}$ & $4.8 \pm 0.4^{* *}$ \\
$P_{\mathrm{e}}(\%)$ & $18 \%$ & $29 \%$ & $35 \%$ & $47 \%$ & $0.06 \pm 0.05^{* * *}$ \\
$n$ & $10 ; 11$ & $23 ; 14$ & $17 ; 34$ & $22 ; 43$ & $04 \%$ & $26 ; 30$ \\
\hline
\end{tabular}

The number of beads examined $(n)$ is given for the two types of experiments (trap for 2 sec; continuous trap). Ncad-Fc conditions are compared with the Fc coating condition, and the cytochalasin D (CytD) treatment is compared with the $0.3 \mu \mathrm{g} / \mathrm{cm}^{2}$ Ncad-Fc coating, untreated condition.

${ }^{*} p<0.05 ;{ }^{* *} p<0.01 ;{ }^{* * *} p<0.005$.
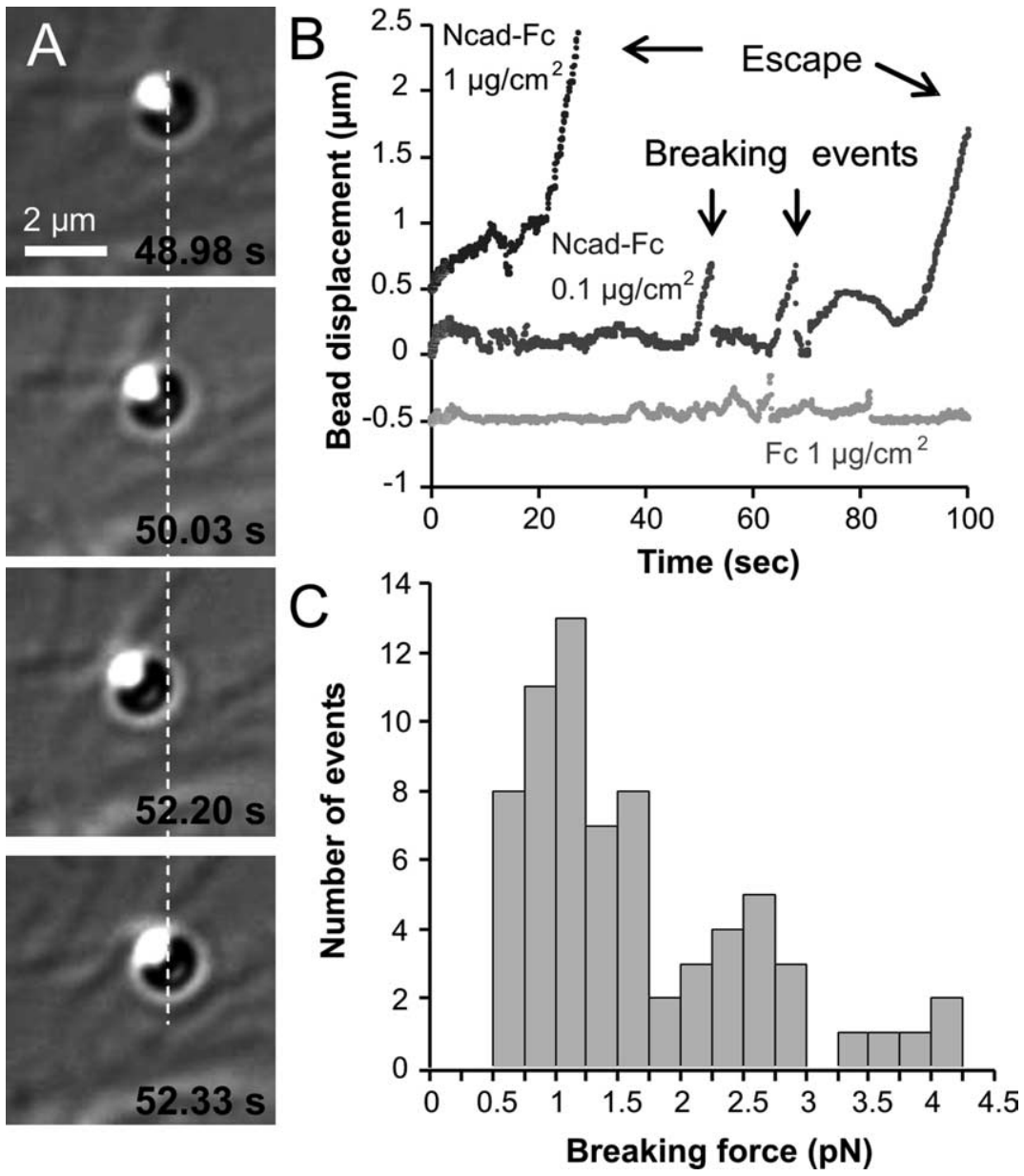

Figure 3. Breaking events displayed by optically restrained $\mathrm{N}$-cadherin-coated microspheres. $\boldsymbol{A}, \mathrm{A}$ microsphere coated with $0.1 \mu \mathrm{g} / \mathrm{cm}^{2} \mathrm{Ncad}-\mathrm{Fc}$ starts to escape $50 \mathrm{~s}$ after initial contact and then quickly comes back into the trap center. The dashed line indicates the equilibrium trapping position. $\boldsymbol{B}$, Corresponding graph showing the distance traveled by the bead with respect to the trap center, versus time. Two breaking events (arrows) were identified in this example (dark gray trace). Final escape appears as a sudden linear increase in displacement over time. Beads coated with $1 \mu \mathrm{g} / \mathrm{cm}^{2} \mathrm{Ncad}$-Fc escape rapidly (black trace), whereas beads coated with Fc alone stay indefinitely in the trap (bottom gray trace). For clarity, the $1 \mu \mathrm{g} / \mathrm{cm}^{2} \mathrm{Ncad}-\mathrm{Fc}$ and Fc traces have been moved up and down by $0.5 \mu \mathrm{m}$, respectively. $\boldsymbol{C}$, Force histogram of all breaking events.

the effects of $\operatorname{Ncad} \Delta \beta$ cat and NcadAAA were less selective, because their expression also reduced neurite extension on laminin by $\sim 30 \%$. There are several possible explanations for this behavior which will be addressed in the discussion.

Next, the coupling of mutated $\mathrm{N}$-cadherin receptors to the actin flow was estimated by optical tweezers (Fig. 5). The rearward velocity of Ncad-Fc beads placed on cells transfected with GFP or NcadWT was slightly reduced when compared with nontransfected counterparts (compare Tables 1,2), indicating that the actin flow was perturbed by the transfection protocol itself. However, given considerable slippage, this velocity was still suf- ficient to allow for growth cone advance at normal speed, leading to normal neurite length for GFP-expressing cells $(\sim 200 \mu \mathrm{m}$ for an Ncad-Fc coating density of $0.3 \mu \mathrm{g} / \mathrm{cm}^{2}$ ) (compare Figs. $1 D, 4 B)$. In addition, Ncad-Fc-coated beads rapidly coupled to the actin flow in neurons transfected with GFP or NcadWT even in the presence of a continuous trap (Fig. $5 A, B$ ), resulting in high escape probability (Fig. $5 C$ ) and coupling index (Fig. 5D), and demonstrating intact $\mathrm{N}$-cadherin anchorage to actin. As for the effect on neurite length, there was a slight and nonsignificant reduction in coupling index for NcadWT, which may be explained by a higher adhesion (see below, Weak correlation between $\mathrm{N}$-cadherin binding strength and growth cone migration, and Discussion). In contrast, Ncad-Fc beads on cells transfected with $\mathrm{Ncad} \Delta$ extra, $\mathrm{Ncad} \Delta \beta \mathrm{cat}$, and NcadAAA showed more difficulty to escape when compared with GFPexpressing counterparts (Fig. 5A-C). Together with reduced bead velocity and increased diffusion coefficient (Table 2), this resulted in significantly lower coupling index for $\mathrm{N}$-cadherin mutants compared with the GFP and NcadWT conditions (Fig. 5D). Although here again the effects of NcadAAA and $\mathrm{Ncad} \Delta \beta$ cat may affect the actin flow in a nonspecific manner (see Discussion), the coupling index was overall strongly correlated with axonal length in these conditions of perturbation of cadherin-catenin interactions (Fig. 5D).

To gain further insight into the molecular interface between $\mathrm{N}$-cadherin receptors and the actin flow, we used another strategy based on RNA interference against $\alpha$-catenin. Because the main $\alpha$-catenin isoform in cultured hippocampal neurons is $\alpha \mathrm{E}$-catenin (supplemental Fig. $2 \mathrm{~A}$, available at www.jneurosci.org as supplemental material), we specifically designed and tested siRNA against $\alpha$ E-catenin, together with control siRNA. Transfection of these siRNA in heterologous cells (supplemental Fig. $2 B, C$, available at www.jneurosci.org as supplemental material) or neurons (Fig. 6A, supplemental Fig. $2 D$, available at www.jneurosci.org as supplemental material) yielded a dramatic downregulation of $\alpha \mathrm{E}$-catenin expression compared with control-transfected cells ( $\sim 50 \%$ measured by immunoblot). Neurons with RNAi against $\alpha \mathrm{E}$-catenin grew significantly shorter neurites on Ncad-Fc-coated substrates than those transfected with control siRNA (Fig. 6A,B). This effect was specific of the $\mathrm{N}$-cadherin adhesive interaction because no significant difference was observed when cells were seeded on polylysine- 
A
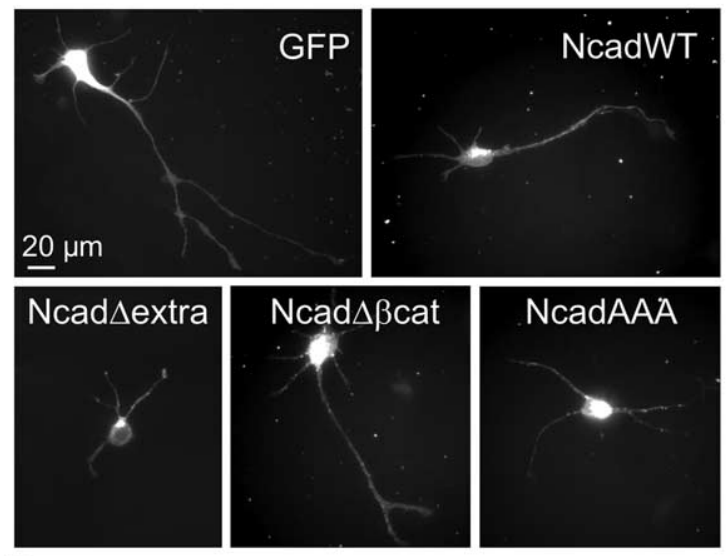

$\mathrm{B}$

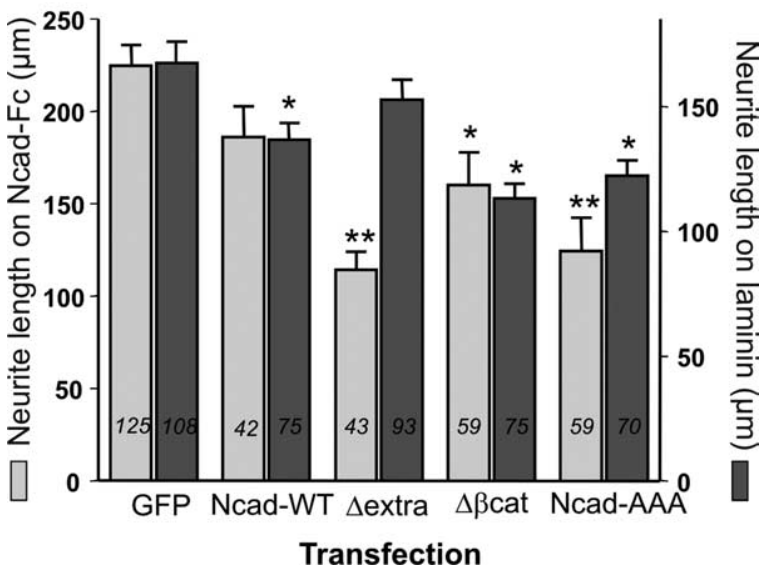

Figure 4. Effect of mutated $\mathrm{N}$-cadherin receptors on neurite outgrowth. Neurons were plated on coverslips coated with $0.3 \mu \mathrm{g} / \mathrm{cm}^{2} \mathrm{Ncad}-\mathrm{Fc}$ or $5 \mu \mathrm{g} / \mathrm{cm}^{2}$ laminin, transfected at 1 DIV with GFP, Ncad-GFP, GFP + Ncad $\Delta$ extra, Ncad $\Delta \beta$ cat-GFP, or NcadAAA-YFP, and observed at 2 DIV. A, Representative GFP fluorescence images for GFP-tagged receptors and anti-myc tag immunostaining for Ncad- $\Delta$ extra. $\boldsymbol{B}$. The length of the longest neurite is plotted for each transfection. The mean lengths obtained for the $\mathrm{N}$-cadherin mutants are compared by ANOVA to the control GFP transfection in each substrate condition. ${ }^{*} p<0.05$; ${ }^{* *} p<0.01$. Error bars indicate SEM.

coated substrates (Fig. 6B). The $\alpha$ E-catenin RNAi also interfered with the ability of Ncad-Fc-coated beads placed on growth cones to escape the optical trap (Fig. $6 C, D$ ). Indeed, the escape probability was reduced by $60 \%$ with respect to control RNA (Fig. $6 E$ ). Thus, reducing specifically $\alpha$-catenin protein expression reduces both neurite extension and coupling efficiency, strongly suggesting that $\alpha \mathrm{E}$-catenin is a key molecule in the connection between $\mathrm{N}$-cadherin adhesion and the retrograde actin flow.

\section{Stiffening of $\mathrm{N}$-cadherin contacts is associated with local} actin recruitment

Despite extensive slippage, growth cones slowly tract themselves on immobilized $\mathrm{N}$-cadherin ligands. In this process, the actin network is likely to generate forces on a small number of sufficiently strong $\mathrm{N}$-cadherin receptor clusters. To examine this issue, we monitored the dynamic behavior of actin and N-cadherin adhesions using dual-color time-lapse imaging of actin-GFP and Ncad-DsRed in growth cones migrating on Ncad-Fc substrates. $\mathrm{N}$-cadherin was rather evenly distributed, but occasionally formed small clusters at the substrate level that could last for 1-2 min (Fig. 7A,B). Actin-GFP often accumulated at these Ncad-
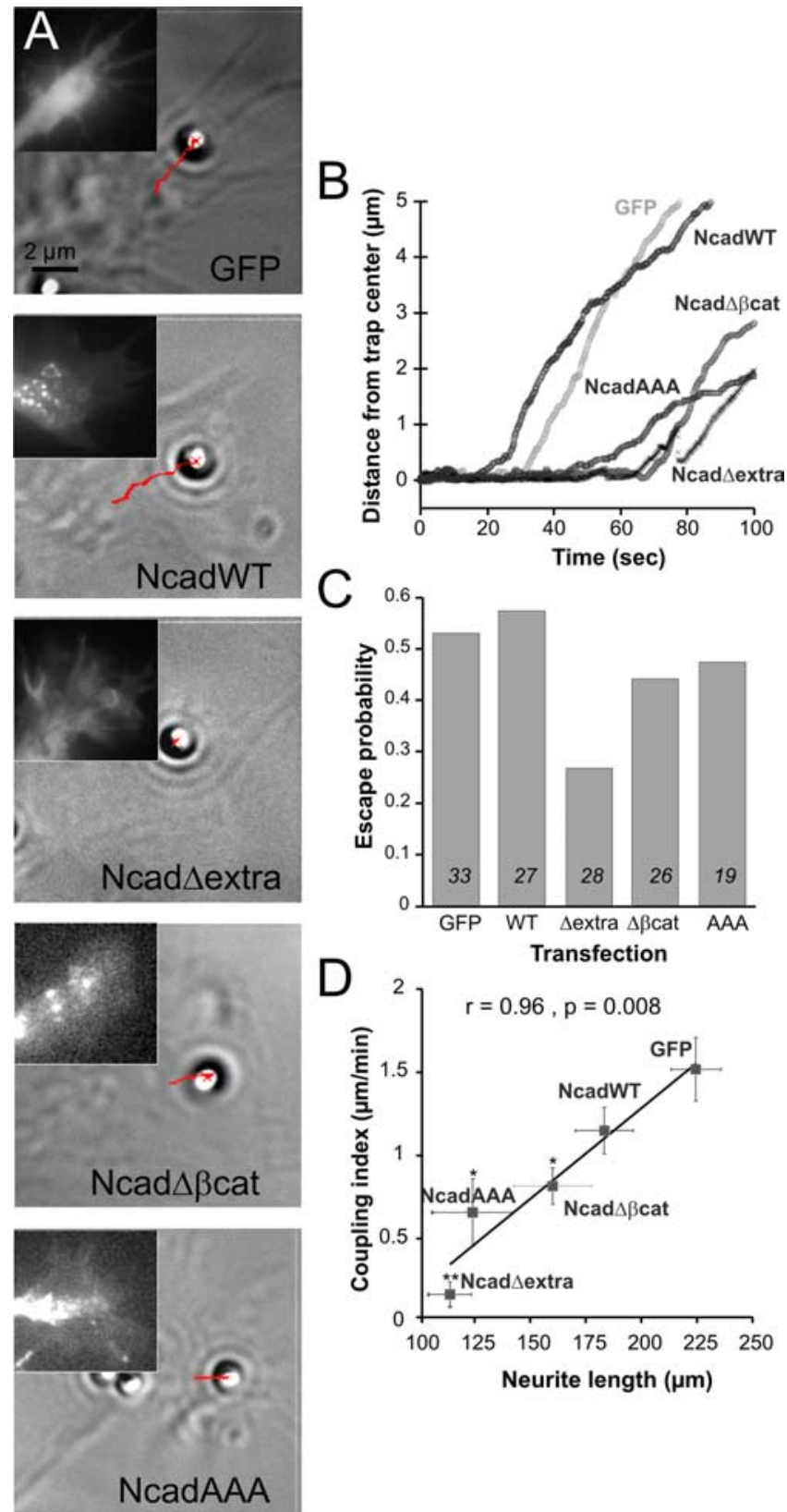

Figure 5. Effect of mutated $\mathrm{N}$-cadherin receptors on receptor-cytoskeleton coupling. Neurons cultured on polylysine were transfected at 1 DIV with each of the five plasmids. At 2 DIV, microspheres coated with $0.3 \mu \mathrm{g} / \mathrm{cm}^{2} \mathrm{Ncad}-\mathrm{Fc}$ were maintained on growth cones for $2 \mathrm{~min}$ by applying optical tweezers continuously. $\boldsymbol{A}$, Representative DIC images and corresponding fluorescence images of GFP-tagged proteins (insets) are presented for each condition. Untagged $\mathrm{Ncad} \Delta$ extra was cotransfected with GFP at a 4:1 ratio, and we checked by retrospective immunostaining that all GFP-positive neurons also expressed $\mathrm{Ncad} \Delta$ extra. Beads are shown at time 0 and trajectories truncated at $1 \mathrm{~min}$ are in red. $\boldsymbol{B}$, Corresponding displacements versus time. $\boldsymbol{C}$, Fraction of beads escaping the trap in $<1 \mathrm{~min}$. $\boldsymbol{D}$, Coupling index versus neurite length for all transfections. ${ }^{*} p<0.05 ;{ }^{* *} p<0.01$.

DsRed-rich clusters, then disappeared as the clusters dissolved (Fig. 7 A, B, supplemental Video 6, available at www.jneurosci.org as supplemental material). These results suggested that the clustering of a few $\mathrm{N}$-cadherin receptors is sufficient to induce local and transient actin accumulation. On average, the level of fluorescence of such clusters normalized by control areas on the same growth cones was $2.08 \pm 0.12$ for actin-GFP and only $1.36 \pm 0.04$ for $\mathrm{N}$-cadherin-DsRed ( $n=22$ clusters from 5 cotransfected cells; $p<0.001$ by Student's $t$ test), revealing a threefold differ- 
Table 2. Parameters characterizing microsphere motion for the various $\mathrm{N}$-cadherin mutants

\begin{tabular}{llllll}
\hline Transfection & GFP & NcadWT & Ncad $\Delta$ extra & Ncad $\Delta \beta$ cat & NcadAAA \\
\hline$D\left(10^{-2} \mu \mathrm{m}^{2} / \mathrm{s}\right)$ & $0.5 \pm 0.1$ & $0.8 \pm 0.1$ & $0.8 \pm 0.3$ & $0.7 \pm 0.1$ & $0.7 \pm 0.3$ \\
$V(\mu \mathrm{m} / \mathrm{min})$ & $3.2 \pm 0.2$ & $3.1 \pm 0.4$ & $1.5 \pm 0.4^{* *}$ & $2.4 \pm 0.2$ & $1.8 \pm 0.3^{*}$ \\
$n$ & 59 & 52 & 16 & 33 & 26
\end{tabular}

The individual measurements of parameters $V$ and $D$ can be quite variable because sometimes beads couple well to the actin flow, resulting in high $V$ values and $D$ coefficients that can be as low as $10^{-6} \mu \mathrm{m} / \mathrm{s}$. Conversely, some beads show only Brownian motion, resulting in high $D$ and $V$ artificially close to zero (it is not the actual actin flow that is reduced, but only the directed bead velocity). Thus, the average differences between conditions are most of the time not significant. Taking the logarithm of $D$ in the coupling index helps reduce the SE. Combined with the average escape probability, one then calculates the coupling index, which provides a reliable readout of the overall behavior, can be used to compare different transfections, and can lead to significant differences.

${ }^{*} p<0.05 ;{ }^{* *} p<0.01$.
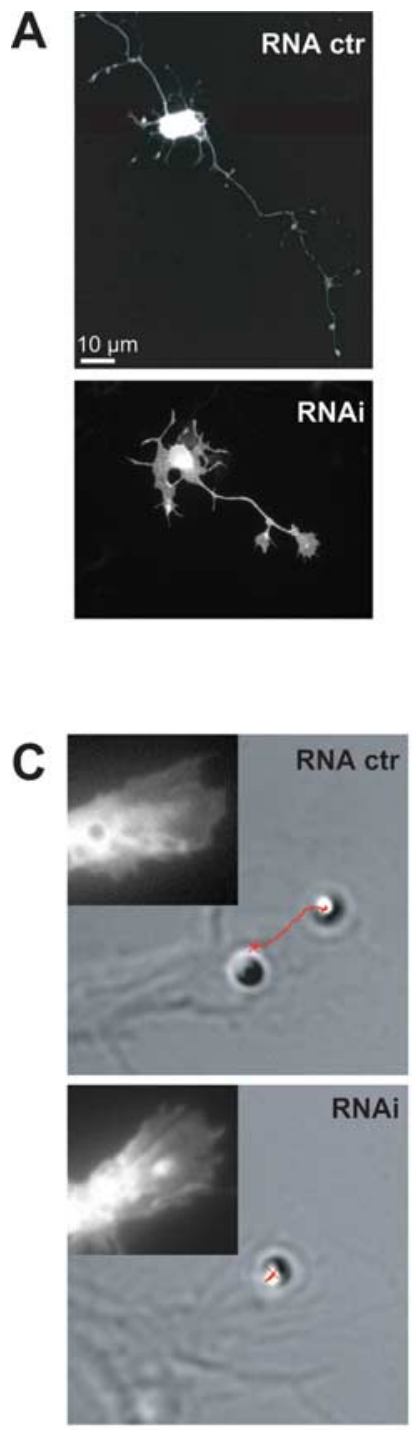

B

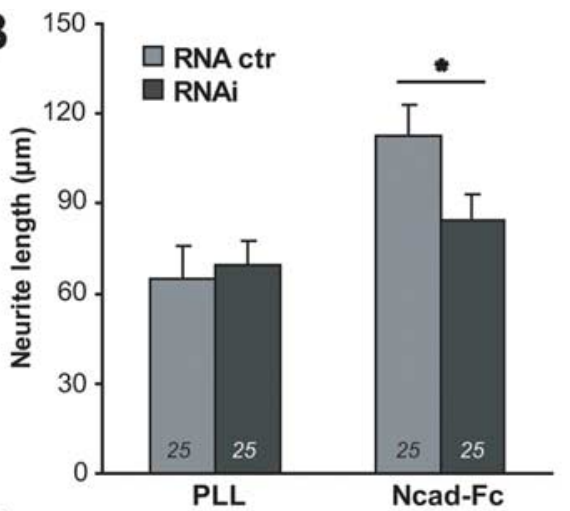

D

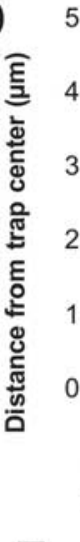

E

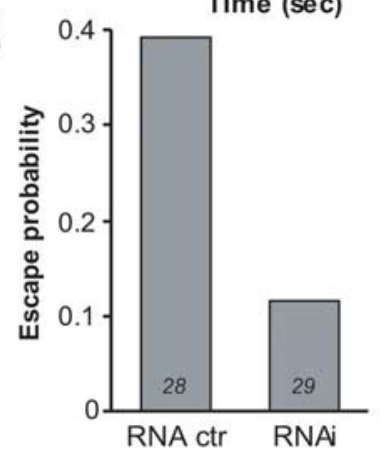

Transfection

Figure 6. Effect of $\alpha$-catenin silencing on neurite outgrowth and N-cadherin-cytoskeleton coupling. Neurons were plated on coverslips coated with $0.3 \mu \mathrm{g} / \mathrm{cm}^{2} \mathrm{Ncad}-\mathrm{Fc}$ or polylysine, transfected $6 \mathrm{~h}$ after seeding with GFP $+\alpha \mathrm{E}$-catenin RNAi duplexes or GFP + RNActr, and processed at 2 DIV. $A$, Effect of $\alpha$ E-catenin siRNA or RNActr on neurite extension on Ncad-Fc. $\boldsymbol{B}$, Length of the longest neurite quantified for the two transfections and the two types of substrates, showing a strong effect of $\alpha \mathrm{E}$-catenin siRNA on neurite extension on $\mathrm{Ncad}-\mathrm{Fc}$, but not on polylysine (PLL). C $\mathrm{E}$, Microspheres coated with $0.3 \mu \mathrm{g} / \mathrm{cm}^{2} \mathrm{Ncad}-\mathrm{Fc}$ were placed on the growth cones of neurons plated on polylysine and transfected with either $\alpha \mathrm{E}$-catenin siRNA or RNActr as the optical trap was applied continuously. C, One example of each condition: red traces represent 2 min trajectories superimposed on the DIC images, and the insets show the corresponding GFP fluorescence. $D_{\text {, }}$ Corresponding displacement versus time plot for these two examples, showing that the bead escapes the trap at $40 \mathrm{sin}$ the case of RNActr, but does not escape before $100 \mathrm{~s}$ in the case of RNAi. $\boldsymbol{E}$, Probability of escape from the trap before $1 \mathrm{~min}$, computed for $\sim 30$ beads in each condition ( $24-30$ neurons for each experiment). Error bars indicate SEM. ${ }^{*} p<0.05$. ence between $\mathrm{N}$-cadherin and actin enrichment at these contact sites with the Ncad-Fc-coated substrate.

We then investigated whether the mechanical resistance at $\mathrm{N}$-cadherin adhesions was involved in such actin accumulation. We mimicked stiff $\mathrm{N}$-cadherin contacts by imposing forces on microspheres coated with maximal Ncad-Fc density, and monitored actin-GFP redistribution. Because the optical trap was too weak to restrain microsphere motion, we used larger beads and prevented them from moving rearward by positioning a stiff microneedle downstream (Suter et al., 1998), resulting in a continuous slippage of the actin flow beneath the microsphere. The force measured by deflection of the microneedle was $\sim 1 \mathrm{nN}$, i.e., the strength of 10-20 homophilic bonds between N-cadherins (Perret et al., 2004; Pittet et al., 2008). Thus, slippage in these conditions is likely to involve the complex and random rupture of many receptor-cytoskeleton bonds, impossible to resolve at the individual level as shown in Figure 3. There was no particular enrichment for actin at unrestrained beads as they traveled rearward (Fig. $8 \mathrm{~A}$ ). In contrast, restrained microspheres showed punctual accumulation of actin at the site of force imposition (Fig. $8 B$, supplemental Video 7, available at www.jneurosci.org as supplemental material), which reached a maximum level in 1-2 min, then stayed rather constant (Fig. $8 C)$. Such actin accumulation displayed kinetics and levels similar to those observed on Ncad-Fc-coated coverslips, suggesting a common molecular mechanism. Similar experiments on cells transfected with Ncad-GFP indicated a much slower and more uniform accumulation of Ncad-GFP receptors around Ncad-Fc-coated beads (Thoumine et al., 2006). Therefore, actin recruitment can be initiated by a moderate accumulation of $\mathrm{N}$-cadherin receptors and is force specific. To confirm that actin accumulation was triggered by a stiff coupling between $\mathrm{N}$-cadherin adhesions and the cytoskeleton, we performed additional micromanipulation experiments on cells coexpressing Ncad $\Delta$ extra to perturb binding between endogenous $\mathrm{N}$-cadherin and the actin flow. In those conditions, only a very transient actinGFP accumulation was observed at the bead contact in the first $2 \mathrm{~min}$, then disappeared in the long term (Fig. 8C,D, supplemental Video 8, available at www. jneurosci.org as supplemental material). Furthermore, when tension was applied forward with the microneedle, we felt very little resistance from these growth cones, in contrast with control cells transfected with actin-GFP alone, in which growth cones crawled toward the tracted beads (supplemental Videos 7, 8, available at www.jneurosci.org as supplemental material).

\section{Weak correlation between $\mathrm{N}$-cadherin binding strength and growth cone migration}

Finally, to determine whether growth cone advance was somehow related to the intrinsic strength of 


\section{A Ncad-DsRed}
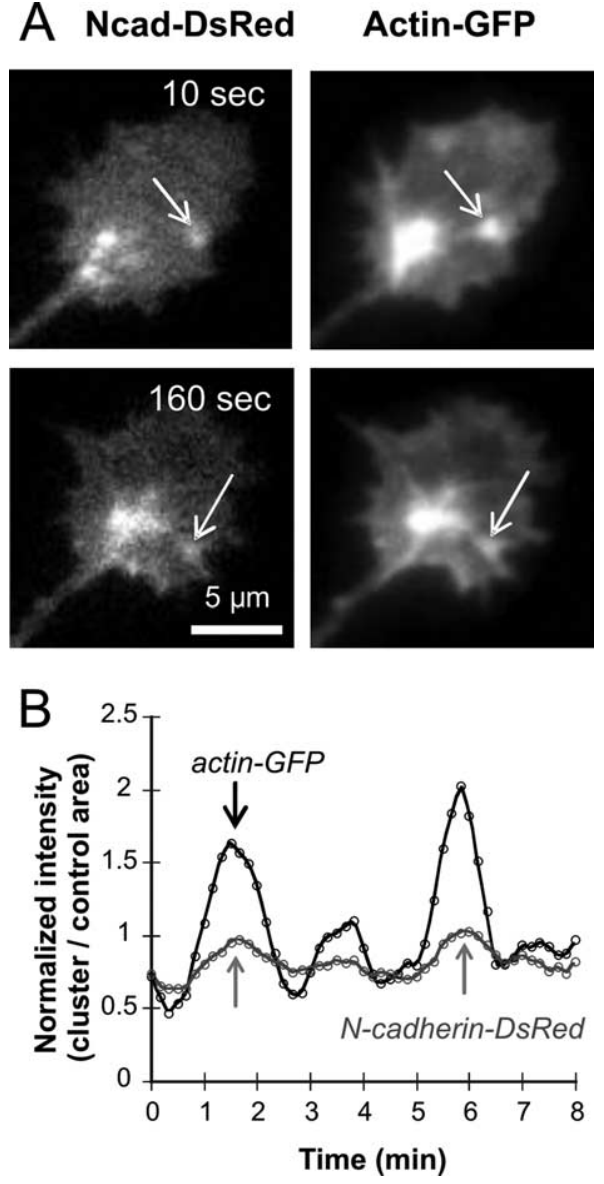

Figure 7. Actin accumulation at basal N-cadherin clusters. Neurons plated on Ncad-Fccoated coverslips were cotransfected with Ncad-DsRed and actin-GFP (1:1). We took care to focus at the substrate level to reveal $\mathrm{N}$-cadherin distribution at the basal membrane. $A$, Example of a growth cone showing transient formation of $\mathrm{N}$-cadherin clusters (arrows) paralleled by a dramatic accumulation of actin. $\boldsymbol{B}$, Example of an $\mathrm{N}$-cadherin cluster that formed and disappeared several times at the same location. The GFP and DsRed fluorescence intensities at the cluster were normalized to those in a nearby region and plotted over time.

$\mathrm{N}$-cadherin adhesions, we measured N-cadherin homophilic adhesiveness in conditions of varying ligand density and overexpressing mutated receptors. Neurons plated on polylysine were incubated for $30 \mathrm{~min}$ with $2 \mu \mathrm{m}$ Ncad-Fc-coated microspheres and nonadherent beads were rinsed away (Fig. 9A,B) or pulled away by centrifuging the cultures upside down (data not shown). We estimate that such protocols produced mechanical forces of $\sim 200-250 \mathrm{pN}$ on the beads (see Materials and Methods), the strength of approximately five cadherin molecular bridges (Perret et al., 2004; Pittet et al., 2008). Therefore, this long-term adhesion assay reflects rather strong contacts involving several $\mathrm{N}$-cadherin molecules. The number of beads remaining bound per cell increased gradually with Ncad-Fc density (supplemental Fig. $3 A$, available at www.jneurosci.org as supplemental material) and was strongly reduced in the presence of EGTA or functionblocking antibodies, indicating adhesion specificity (supplemental Fig. $3 B, C$, available at www.jneurosci.org as supplemental material). We also probed $\mathrm{N}$-cadherin adhesiveness specifically at growth cones by placing $1 \mu \mathrm{m}$ microspheres for $2 \mathrm{~s}$ at their periphery using optical tweezers (Fig. 2). The beads that diffused away in the bath after initial contact were scored as nonattached. This allowed calculation of the fraction of adherent beads $P_{\mathrm{a}}$, which measures whether adhesion force is greater than the ther-
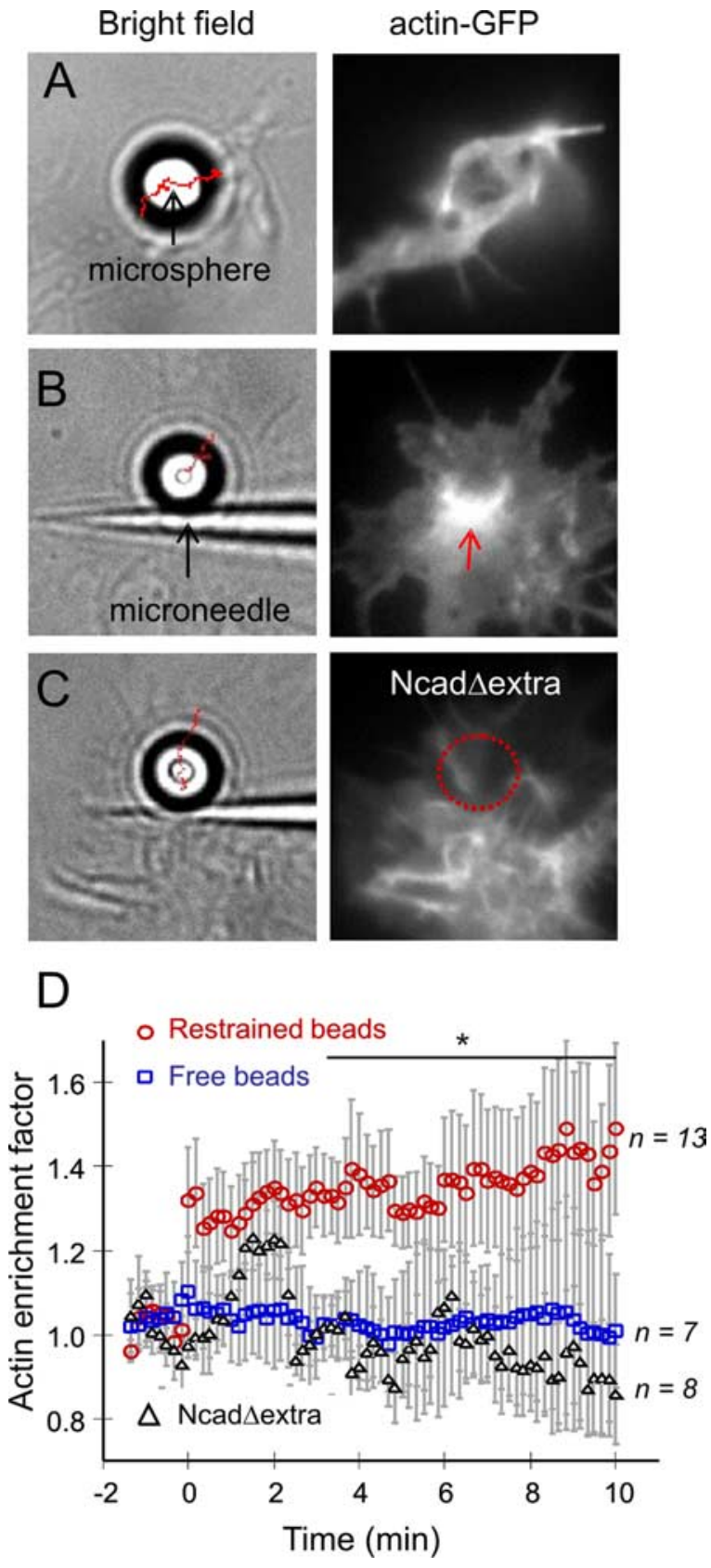

Figure 8. Local actin accumulation at restrained Ncad-Fc microspheres. $\boldsymbol{A}-\boldsymbol{C}$, Neurons seeded on polylysine were transfected with actin-GFP alone $(\boldsymbol{A}, \boldsymbol{B})$ or cotransfected with actinGFP and Ncad $\Delta$ extra $(\boldsymbol{C})$ and observed simultaneously in bright field (left) and fluorescence (right). At time 0, $4 \mu \mathrm{m}$ microspheres coated with $0.3 \mu \mathrm{g} / \mathrm{cm}^{2} \mathrm{Ncad}-\mathrm{Fc}$ were placed on growth cones with optical tweezers, then either left alone $(\boldsymbol{A})$ or immediately restrained with a glass microneedle $(\boldsymbol{B}, \boldsymbol{C})$. Trajectories of $10 \mathrm{~min}$ appear in red and beads are shown 2 min after positioning. Unrestrained microspheres move rearward $(\boldsymbol{A})$, whereas restrained beads are pulled by the experimenter in the direction of growth cone motion (from bottom to top in $B, C$ ). A punctual accumulation of actin-GFP was observed at the locus of force application for restrained beads (arrow), which was absent in control conditions, i.e., unrestrained beads $(\boldsymbol{A})$ or cells expressing of Ncad $\Delta$ extra (C). D, An enrichment factor was defined as the fluorescence signal at the bead contact divided by that in a control area on the same growth cone and plotted versus time. Error bars indicate SEM. ${ }^{*} p<0.05$.

mal motion of the bead. This short-term assay showed basically the same trend as the sedimentation assay (Figs. 9, supplemental Fig. 3, available at www.jneurosci.org as supplemental material). As expected, the effect of $\mathrm{N}$-cadherin on growth cone advance and neurite extension was positively related to the degree of 

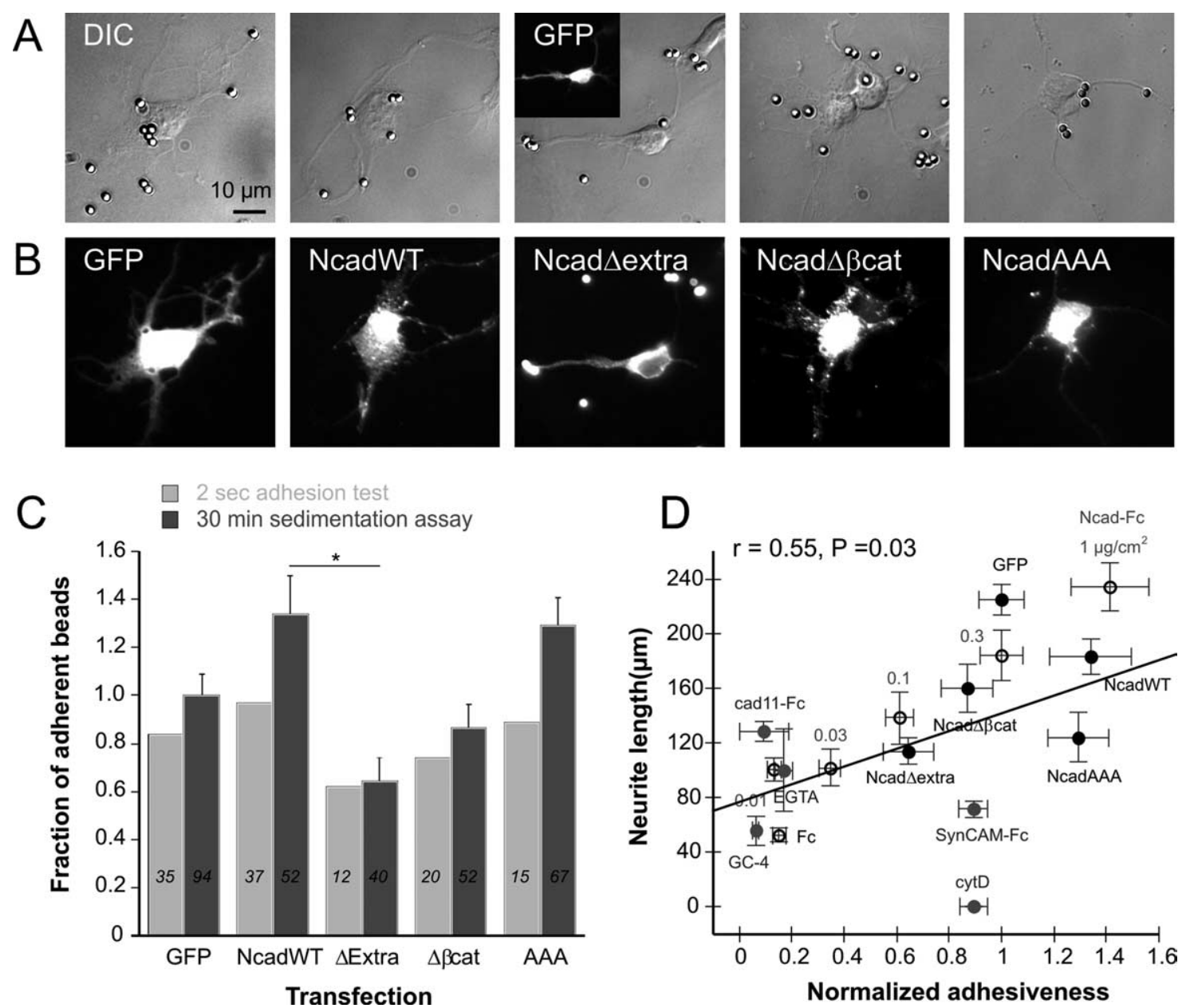

Figure 9. Adhesiveness of N-cadherin mutants. Neurons cultured on polylysine were transfected at 1 DIV for each of the five plasmids: GFP, NcadWT-GFP, Ncad $\Delta$ extra, Ncad $\Delta \beta$ cat-GFP, or NcadAAA-YFP. At 2 DIV, neurons were incubated for 30 min with $2 \mu \mathrm{m}$ microspheres coated with $0.3 \mu \mathrm{g} / \mathrm{cm}^{2} \mathrm{Ncad}-\mathrm{Fc}$, and nonadherent beads were rinsed away. $A, B$, Representative DIC images $(\boldsymbol{A})$ and corresponding fluorescence images $(\boldsymbol{B})$ are presented for each condition. GFP-tagged proteins were detected using anti-GFP immunostaining in permeabilized conditions. Ncad $\Delta$ extra was detected with a monoclonal antibody against an N-cadherin intracellular epitope. Beads are bright because the secondary anti-mouse antibody recognizes mouse $\mathrm{Fc}-\mathrm{Ncad}$ on the bead surface. $\mathrm{C}$, The number of adherent beads per cell is normalized versus the control GFP condition. The fraction of beads staying on growth cones after a $2 \mathrm{~s}$ contact duration by optical tweezers is also plotted for each transfection (light gray bars). This is a probability that does not allow the calculation of an error bar. $D$, Neurite length versus $\mathrm{N}$-cadherin adhesiveness for Ncad-Fc dilutions (white circles), other ligands and perturbation conditions (gray circles), and mutant receptors (black circles). The number of adherent beads per cell in the sedimentation assay was normalized versus the $0.3 \mu \mathrm{g} / \mathrm{cm}^{2}$ Ncad-Fc or GFP conditions, respectively. The line indicates a linear fit through all the data. Note that the correlation parameter is much weaker than with the coupling index (Figs. $2 \mathrm{H}, 5 \mathrm{D})$. Error bars indicate SEM. ${ }^{*} p<0.05$.

N-cadherin homophilic adhesion, but there were a few counter examples. For example, the actin-depolymerizing agent cytochalasin $\mathrm{D}$ arrested growth cone progression (Fig. $2 \mathrm{H}$ ) without affecting $\mathrm{N}$-cadherin adhesiveness (supplemental Fig. $3 A, C$, available at www.jneurosci.org as supplemental material). Also, overexpression of NcadWT and Ncad-AAA receptors increased bead binding (Fig. 9C) but reduced neurite extension (Fig. 4B). In contrast, neurons transfected with Ncad $\Delta$ extra and $\mathrm{Ncad} \Delta \beta$ cat showed a modest reduction in adhesiveness (Fig. $9 C)$, in agreement with the finding that cadherin binding to $\beta$-catenin strengthens adhesion (Chu et al., 2004). Overall, there was a relatively weak correlation between ligand adhesiveness and axonal growth (Fig. 9D). This observation supports the notion that, beyond binding, $\mathrm{N}$-cadherin coupling to the cytoskeleton is a clearer determinant of growth cone advance.

\section{Discussion}

We addressed here the issue of how $\mathrm{N}$-cadherin adhesion couples to actin dynamics to allow for the locomotion of neuronal growth cones. We specifically tested the clutch model, which views the retrograde actin flow as a motor that idles when it does not encounter adhesion to connect to, but which can engage into forward motion providing sufficiently strong transmembrane coupling to substrate-immobilized ligands (Mitchison and Kirschner, 1988; Suter and Forscher, 1998). We used primary neurons interacting with plane substrates or microspheres coated with purified recombinant N-cadherin. Such a biomimetic system allows a precise control of the type and density of ligand molecules presented to the cells and of the initial time of the interaction, which is not possible in natural contacts that form at arbitrary moments and where different types of adhesion proteins can coexist in unknown stoichiometry. The experimental design is summarized in Figure 10.

Our main result is a strong correlation between the rate of growth cone advance on $\mathrm{N}$-cadherin and the mechanical coupling between ligand-bound $\mathrm{N}$-cadherin receptors and the actin flow, in conditions of varying ligand density and expressing mutated $\mathrm{N}$-cadherin receptors. In contrast, when $\mathrm{N}$-cadherin binding alone was measured using bead adhesion assays, we observed 

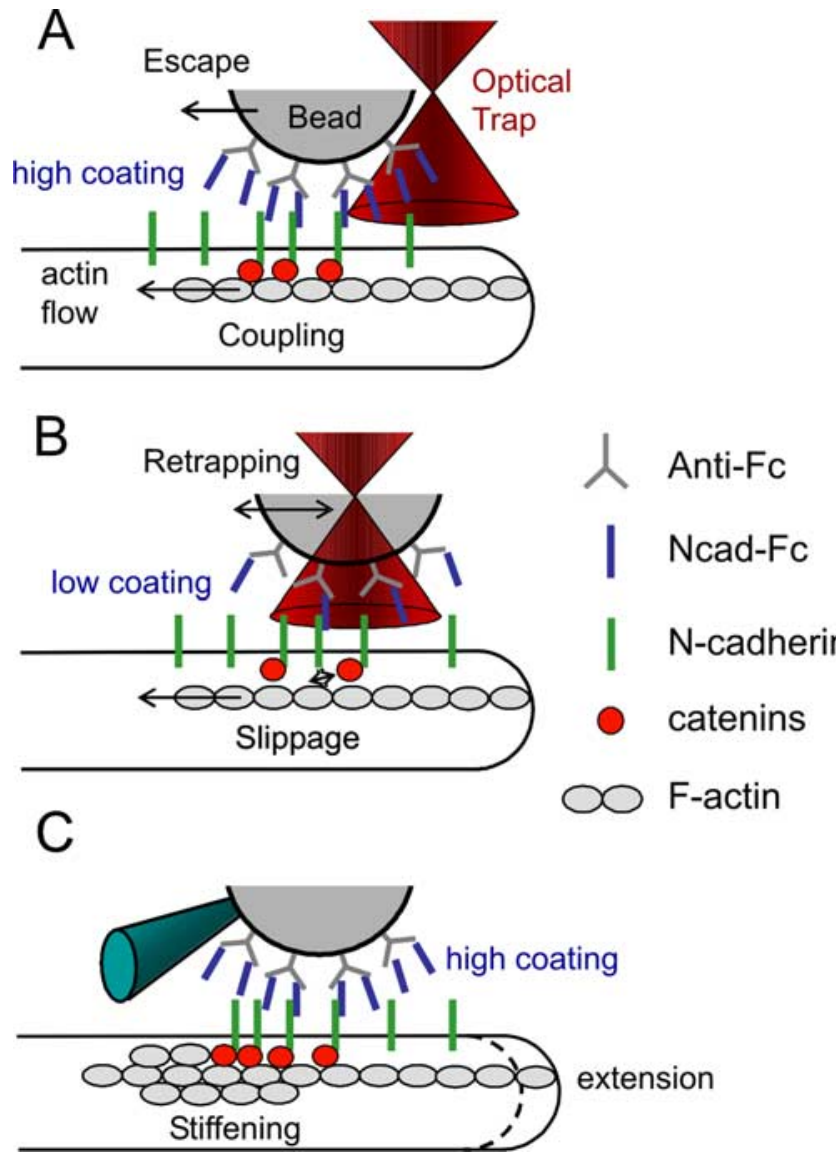

Figure 10. Summary diagram of the main findings. $A$, At a high Ncad-Fc coating density on the microsphere, corresponding to a highly adhesive substrate, there are many ligand-receptoractin bonds formed, resulting in strong coupling to the retrograde flow and bead escape from optical tweezers. This mimics a compliant substrate that would not offer enough resistance to cell traction. $\boldsymbol{B}$, At lower Ncad-Fc density corresponding to a weakly adhesive substrate, there are only a few ligand-receptor bonds formed, not enough to stably connect the bead to the actin retrograde flow. Occasionally, a ligand-receptor-actin linkage is formed, and the bead starts to move rearward, but the rupture of an individual bond at the catenin level at $\mathrm{pN}$ forces causes the bead to snap back into the optical trap. C, At a high Ncad-Fc coating density, the bead is restrained from moving rearward with a rigid microneedle, mimicking a stiff substrate. This induces local actin accumulation at the bead, which stiffens the contact and allows the growth cone to grasp the substrate and move forward.

a much weaker correlation between ligand adhesiveness and axonal growth, confirming previous results reported for DRG neurons plated on $\mathrm{N}$-cadherin, $\mathrm{L} 1$, or polylysine substrates (Lemmon et al., 1992). Thus, our data support a direct mechanical linkage between ligand-bound $\mathrm{N}$-cadherin receptors and the rearwardmoving actin network, allowing traction forces to be transmitted to the substrate and resulting in forward progression (Mitchison and Kirschner, 1988; Suter and Forscher, 1998). The coupling process is likely to be regulated selectively for each adhesion molecule, as demonstrated for the IgCAM member L1, which can engage the actin flow through ankyrin as neurites are initiated, but not as axons extend (Gil et al., 2003; Nishimura et al., 2003). Such spatial control seems to be specific for L1, because L1 is also actively recycled from the base to the tip of growth cones through clathrin-dependent trafficking, and thereby exhibits a distribution gradient at the growth cone surface (Kamiguchi and Yoshihara, 2001; Dequidt et al., 2007).

Here, we focused on the later stages of axon elongation and showed that only N-cadherin had a strong ability to both promote growth cone translocation and couple to the actin flow.
Indeed, the control molecule cadherin-11 showed very poor coupling but slightly promoted axonal growth (Fig. $2 \mathrm{H}$ ), an effect that may involve a transduction pathway involving extracellular cis-binding to the FGF receptor (Saffell et al., 1997; Boscher and Mege, 2008). Conversely, SynCAM, which was reported to act as a trans-synaptic bridge through strong homophilic binding (Biederer et al., 2002; Breillat et al., 2007), coupled rather well to the actin flow but was completely unable to sustain growth cone progression. One possibility to explain this result is that synCAM adhesions are so robust that they cannot detach, and thereby impair growth cone advance. Such effect was reported for fibroblasts migrating on fibronectin, where at high levels of cellsubstratum adhesiveness, cell speed is rate limited by the disruption of cytoskeleton-integrin-extracellular matrix linkages at the rear (Palecek et al., 1997). In that respect, the lifetime of $\mathrm{N}$-cadherin adhesions at neuronal growth cones measured by fluorescence recovery after photobleaching (FRAP) experiments on Ncad-Fc-coated bead contacts lies in the range of several tens of minutes (Thoumine et al., 2006). This precisely fits the duration it would take for an adhesion formed at the growth cone periphery to detach at the rear (i.e., $\sim 10 \mu \mathrm{m}$ further), the growth cone traveling at a velocity of $0.1-1 \mu \mathrm{m} / \mathrm{min}$. Such relatively rapid turnover of $\mathrm{N}$-cadherin adhesions seems to be especially adapted to allow the locomotion of growth cones from hippocampal neurons. As another example, the NcadAAA mutant, which shows a threefold higher homophilic bond lifetime than NcadWT (Thoumine et al., 2006), also shows a reduction in neurite progression that may be linked to high adhesiveness.

Transfection of $\mathrm{N}$-cadherin receptors mutated in cateninbinding regions reduced both cytoskeletal coupling and neurite extension, demonstrating that the clutch directly involves catenin partners. The Ncad $\Delta$ extra mutant, which carries only the transmembrane domain and intracellular tail of $\mathrm{N}$-cadherin, acts as a direct competitor at the cell surface for $\mathrm{N}$-cadherin interactions with all intracellular partners, and as such had the most pronounced and specific effects in these assays. We attempted to use $\mathrm{Ncad} \Delta \beta$ cat and NcadAAA constructs to more selectively perturb catenin interactions, reasoning that by competing for Ncad-Fc ligand binding on the beads, these mutated receptors should reduce the coupling between endogenous $\mathrm{N}$-cadherin receptors and actin, and consequently growth cone velocity on Ncad-Fc. Indeed, $\beta$-catenin is well known to physically link cadherin receptors to actin filaments through binding to $\alpha$-catenin (Mege et al., 2006). Conversely, p120 catenin is known to modulate cadherin adhesiveness (Ozawa and Kemler, 1998; Yap et al., 1998; Thoumine et al., 2006) and was reported to bind cortactin (El Sayegh et al., 2004), providing a potential parallel pathway to connect $\mathrm{N}$-cadherin to the actin network. However, the effects of $\mathrm{Ncad} \Delta \beta$ cat and NcadAAA were not completely specific of the Ncad-Fc substrate, as these mutants also reduced neurite extension on laminin-coated glass. This may be attributable in part to a potential cross talk between cadherins and integrins (e.g., the juxtamembrane domain of cadherin where p120 binds was shown to regulate integrin-mediated adhesion and neurite outgrowth) (Lilien et al., 1999), and N-cadherin is part of a protein complex including NCAM, which stimulates neurite outgrowth by an integrin- and FGF receptor-dependent mechanism (Cavallaro et al., 2001). Nevertheless, $\mathrm{Ncad} \Delta \beta$ cat also exhibits a higher adhesive turnover rate as measured by FRAP (Thoumine et al., 2006), resulting in reduced adhesiveness (Fig. 9), and as such does not act as a good competitor for ligand binding. Furthermore, we noted a systematic reduction of Ncad-Fc bead velocity in growth cones of NcadAAA-transfected neurons, reflecting a slower actin 
flow rate, which may explain the higher inhibitory effect of NcadAAA on neurite length. One mechanism by which expression of NcadAAA could slow down the retrograde actin flow would be to leave a fraction of p120 free to interact with other partners, such as small GTPases (Rac/Rho), which are known to affect actin dynamics (Elia et al., 2006). Alternatively, because p120 is implicated in the recycling of $\mathrm{N}$-cadherin at the plasma membrane (Chen et al., 2003; Davis et al., 2003), it is possible that the reduction of growth cone advance observed for the NcadAAA mutant on Ncad-Fc substrate is attributable to such altered trafficking. Overall, these observations may explain results from in vivo experiments on retinal ganglion cells, which showed that the $\mathrm{N}$-cadherin intracellular tail region upstream of the $\beta$-catenin binding site, where p120 binds, was critical for axonogenesis (Riehl et al., 1996).

Thus, the use of mutated receptors reaching some limits, we adopted a different strategy using siRNA against $\alpha$-catenin. The efficient downregulation of $\alpha$-catenin in neurons led to a specific inhibition of neurite extension on Ncad-Fc substrates and coupling to actin, which represents the best evidence for catenin implication in the clutch mechanism. These data fit nicely with the newly emerging role for $\alpha$-catenin as a key molecule at the interface between intercellular adhesion and actin dynamics (Kobielak and Fuchs, 2004; Drees et al., 2005).

By showing recapture events in the optical trap, we also provide strong evidence for the continuous slippage of bonds between $\mathrm{N}$-cadherin receptors and actin at low forces. Since those beads coated with a small number of $\mathrm{N}$-cadherin ligands are likely to attach to very few receptors (Thoumine and Meister, 2000), the retrapping events were interpreted as the breaking of a small number of molecular bonds. Because the forces involved are much lower than the $30-100 \mathrm{pN}$ interaction between individual cadherin molecules (Perret et al., 2004; Pittet et al., 2008), and because beads remain attached to the growth cone surface when the trap is stopped, rupture is unlikely to occur between $\mathrm{N}$-cadherin ligands and receptors. Instead, the $1 \mathrm{pN}$ retrapping events more likely correspond to the rupture of single bonds between the cadherin-catenin complex and actin, which were proposed previously to be highly dynamic (Drees et al., 2005). The higher force values may represent multiples of the unitary 1 $\mathrm{pN}$ value, and correspond to the simultaneous breakage of several bonds. The forces involved here are similar to the $2 \mathrm{pN}$ bond between integrin trimers and the actin cytoskeleton through talin reported in fibroblasts (Jiang et al., 2003), suggesting that slippage at low forces is a general mechanism underlying actin anchorage to substrate-bound ligands.

By applying higher forces, we were able to restrain microspheres and locally stop the actin flow. We then observed striking accumulation of actin-GFP at the bead contact, which was also seen at sites of $\mathrm{N}$-cadherin clusters touching the substrate. The fact that in both assays, actin accumulated to greater levels than $\mathrm{N}$-cadherin receptors confirms the different dynamics of actin and cadherin-catenin complexes at adhesion sites (Yamada et al., 2005) and suggests some sort of amplification, not only a passive recruitment of pre-existing actin filaments. We propose a mechanism based on a local actin polymerization driven by mechanical force applied at $\mathrm{N}$-cadherin receptor clusters, as observed in myogenic cells using patterned force detection with micropillar arrays (Ganz et al., 2006). It is possible that nascent N-cadherin adhesions may initiate such process by mobilizing $\alpha$-catenin molecules otherwise in competition with the Arp2/3 nucleating complex (Drees et al., 2005). Indeed, an accumulation of $\alpha$-catenin-GFP was also observed in the microneedle assay (data not shown) and the recruitment of actin at microspheres was prevented by overexpression of the Ncad $\Delta$ extra mutant, which competed for the binding of catenin partners. Alternatively, actin accumulation may be linked to other pathways, for example, activation of Racl, which we previously reported to mediate $\mathrm{N}$-cadherin anchoring to the actin flow (Lambert et al., 2002), or FGF receptor activation and downstream signaling through the phospholipase C- $\gamma /$ DAG lipase pathway and calcium regulation (Saffell et al., 1997; Boscher and Mege, 2008). In any case, local actin accumulation at stiff $\mathrm{N}$-cadherin contacts may serve to strengthen the adhesive complex and act as a driving force for growth cone extension downstream of $\mathrm{N}$-cadherin liganding.

In conclusion, our data suggest that $\mathrm{N}$-cadherin exerts a neuritogenic effect in neurons from the CNS of vertebrates by stimulating growth cone migration via a molecular clutch mechanism, catenins being part of the force-transducing complex to actin filaments.

\section{References}

Bekirov IH, Nagy V, Svoronos A, Huntley GW, Benson DL (2007) Cadherin-8 and N-cadherin differentially regulate presynaptic and postsynaptic development of the hippocampal mossy fiber pathway. Hippocampus 18:349-363.

Benson DL, Tanaka H (1998) N-cadherin redistribution during synaptogenesis in hippocampal neurons. J Neurosci 18:6892-6904.

Biederer T, Sara Y, Mozhayeva M, Atasoy D, Liu X, Kavalali ET, Sudhof TC (2002) SynCAM, a synaptic adhesion molecule that drives synapse assembly. Science 297:1525-1531.

Boscher C, Mege RM (2008) Cadherin-11 interacts with the FGF receptor and induces neurite outgrowth through associated downstream signalling. Cell Signal 20:1061-1072.

Bozdagi O, Shan W, Tanaka H, Benson DL, Huntley GW (2000) Increasing numbers of synaptic puncta during late-phase LTP: $\mathrm{N}$-cadherin is synthesized, recruited to synaptic sites, and required for potentiation. Neuron 28:245-259.

Bradke F, Dotti CG (1997) Neuronal polarity: vectorial cytoplasmic flow precedes axon formation. Neuron 19:1175-1186.

Breillat C, Thoumine O, Choquet D (2007) Characterization of SynCAM surface trafficking using a SynCAM derived ligand with high homophilic binding affinity. Biochem Biophys Res Commun 359:655-659.

Cavallaro U, Niedermeyer J, Fuxa M, Christofori G (2001) N-CAM modulates tumour-cell adhesion to matrix by inducing FGF-receptor signalling. Nat Cell Biol 3:650-657.

Chen X, Kojima S, Borisy GG, Green KJ (2003) p120 catenin associates with kinesin and facilitates the transport of cadherin-catenin complexes to intercellular junctions. J Cell Biol 163:547-557.

Chu YS, Thomas WA, Eder O, Pincet F, Perez E, Thiery JP, Dufour S (2004) Force measurements in E-cadherin-mediated cell doublets reveal rapid adhesion strengthened by actin cytoskeleton remodeling through Rac and Cdc42. J Cell Biol 167:1183-1194.

Davis MA, Ireton RC, Reynolds AB (2003) A core function for p120-catenin in cadherin turnover. J Cell Biol 163:525-534.

Dequidt C, Danglot L, Alberts P, Galli T, Choquet D, Thoumine O (2007) Fast turnover of $\mathrm{L} 1$ adhesions in neuronal growth cones involving both surface diffusion and exo/endocytosis of L1 molecules. Mol Biol Cell 18:3131-3143.

Diefenbach TJ, Latham VM, Yimlamai D, Liu CA, Herman IM, Jay DG (2002) Myosin 1c and myosin IIB serve opposing roles in lamellipodial dynamics of the neuronal growth cone. J Cell Biol 158:1207-1217.

Drees F, Pokutta S, Yamada S, Nelson WJ, Weis WI (2005) Alpha-catenin is a molecular switch that binds E-cadherin-beta-catenin and regulates actin-filament assembly. Cell 123:903-915.

Elia LP, Yamamoto M, Zang K, Reichardt LF (2006) p120 catenin regulates dendritic spine and synapse development through Rho-family GTPases and cadherins. Neuron 51:43-56.

El Sayegh TY, Arora PD, Laschinger CA, Lee W, Morrison C, Overall CM, Kapus A, McCulloch CA (2004) Cortactin associates with N-cadherin adhesions and mediates intercellular adhesion strengthening in fibroblasts. J Cell Sci 117:5117-5131.

Eugene E, Depienne C, Baulac S, Baulac M, Fritschy JM, Le Guern E, Miles R, 
Poncer JC (2007) GABA(A) receptor gamma 2 subunit mutations linked to human epileptic syndromes differentially affect phasic and tonic inhibition. J Neurosci 27:14108-14116.

Fischer M, Kaech S, Knutti D, Matus A (1998) Rapid actin-based plasticity in dendritic spines. Neuron 20:847-854.

Ganz A, Lambert M, Saez A, Silberzan P, Buguin A, Mege RM, Ladoux B (2006) Traction forces exerted through N-cadherin contacts. Biol Cell 98:721-730.

Gil OD, Sakurai T, Bradley AE, Fink MY, Cassella MR, Kuo JA, Felsenfeld DP (2003) Ankyrin binding mediates L1CAM interactions with static components of the cytoskeleton and inhibits retrograde movement of L1CAM on the cell surface. J Cell Biol 162:719-730.

Goslin K, Asmussen H, Banker G (1991) Rat hippocampal neurons in lowdensity culture. In: Culturing nerve cells, Ed 2 (Banker G, Goslin K, eds), pp 339-370. Cambridge, MA: MIT.

Jiang G, Giannone G, Critchley DR, Fukumoto E, Sheetz MP (2003) Twopiconewton slip bond between fibronectin and the cytoskeleton depends on talin. Nature 424:334-337.

Kadowaki M, Nakamura S, Machon O, Krauss S, Radice GL, Takeichi M (2007) N-cadherin mediates cortical organization in the mouse brain. Dev Biol 304:22-33.

Kamiguchi H, Yoshihara F (2001) The role of endocytic 11 trafficking in polarized adhesion and migration of nerve growth cones. J Neurosci 21:9194-9203.

Kobielak A, Fuchs E (2004) Alpha-catenin: at the junction of intercellular adhesion and actin dynamics. Nat Rev Mol Cell Biol 5:614-625.

Kucik DF, Kuo SC, Elson EL, Sheetz MP (1991) Preferential attachment of membrane glycoproteins to the cytoskeleton at the leading edge of lamella. J Cell Biol 114:1029-1036.

Kucik DF, Elson EL, Sheetz MP (1999) Weak dependence of mobility of membrane protein aggregates on aggregate size supports a viscous model of retardation of diffusion. Biophys J 76:314-322.

Lambert M, Padilla F, Mege RM (2000) Immobilized dimers of $\mathrm{N}$-cadherin-Fc chimera mimic cadherin-mediated cell contact formation: contribution of both outside-in and inside-out signals. J Cell Sci 113:2207-2219.

Lambert M, Choquet D, Mege RM (2002) Dynamics of ligand-induced, Rac1-dependent anchoring of cadherins to the actin cytoskeleton. J Cell Biol 157:469-479.

Lambert M, Thoumine O, Brevier J, Choquet D, Riveline D, Mege RM (2007) Nucleation and growth of cadherin adhesions. Exp Cell Res 313:4025-4040.

Lamoureux P, Ruthel G, Buxbaum RE, Heidemann SR (2002) Mechanical tension can specify axonal fate in hippocampal neurons. J Cell Biol 159:499-508.

Lemmon V, Burden SM, Payne HR, Elmslie GJ, Hlavin ML (1992) Neurite growth on different substrates: permissive versus instructive influences and the role of adhesive strength. J Neurosci 12:818-826.

Lilien J, Arregui C, Li H, Balsamo J (1999) The juxtamembrane domain of cadherin regulates integrin-mediated adhesion and neurite outgrowth. J Neurosci Res 58:727-734.

Lin CH, Forscher P (1995) Growth cone advance is inversely proportional to retrograde F-actin flow. Neuron 14:763-771.

Lin CH, Espreafico EM, Mooseker MS, Forscher P (1996) Myosin drives retrograde F-actin flow in neuronal growth cones. Neuron 16:769-782.

Mallavarapu A, Mitchison T (1999) Regulated actin cytoskeleton assembly at filopodium tips controls their extension and retraction. J Cell Biol 146:1097-1106.

Marthiens V, Gavard J, Padilla F, Monnet C, Castellani V, Lambert M, Mege RM (2005) A novel function for cadherin-11 in the regulation of motor axon elongation and fasciculation. Mol Cell Neurosci 28:715-726.
Matsunaga M, Hatta K, Nagafuchi A, Takeichi M (1988) Guidance of optic nerve fibres by $\mathrm{N}$-cadherin adhesion molecules. Nature 334:62-64.

Mege RM, Gavard J, Lambert M (2006) Regulation of cell-cell junctions by the cytoskeleton. Curr Opin Cell Biol 18:541-548.

Mitchison T, Kirschner M (1988) Cytoskeletal dynamics and nerve growth. Neuron 1:761-772.

Nishimura K, Yoshihara F, Tojima T, Ooashi N, Yoon W, Mikoshiba K, Bennett V, Kamiguchi H (2003) L1-dependent neuritogenesis involves ankyrinB that mediates L1-CAM coupling with retrograde actin flow. J Cell Biol 163:1077-1088.

Okamura K, Tanaka H, Yagita Y, Saeki Y, Taguchi A, Hiraoka Y, Zeng LH, Colman DR, Miki N (2004) Cadherin activity is required for activityinduced spine remodeling. J Cell Biol 167:961-972.

Ozawa M, Kemler R (1998) The membrane-proximal region of the E-cadherin cytoplasmic domain prevents dimerization and negatively regulates adhesion activity. J Cell Biol 142:1605-1613.

Palecek SP, Loftus JC, Ginsberg MH, Lauffenburger DA, Horwitz AF (1997) Integrin-ligand binding properties govern cell migration speed through cell-substratum adhesiveness. Nature 385:537-540.

Perret E, Leung A, Feracci H, Evans E (2004) Trans-bonded pairs of E-cadherin exhibit a remarkable hierarchy of mechanical strengths. Proc Natl Acad Sci USA 101:16472-16477.

Pittet P, Lee K, Kulik AJ, Meister JJ, Hinz B (2008) Fibrogenic fibroblasts increase intercellular adhesion strength by reinforcing individual OBcadherin bonds. J Cell Sci 121:877-886.

Riehl R, Johnson K, Bradley R, Grunwald GB, Cornel E, Lilienbaum A, Holt CE (1996) Cadherin function is required for axon outgrowth in retinal ganglion cells in vivo. Neuron 17:837-848.

Saffell JL, Williams EJ, Mason IJ, Walsh FS, Doherty P (1997) Expression of a dominant negative FGF receptor inhibits axonal growth and FGF receptor phosphorylation stimulated by CAMs. Neuron 18:231-242.

Saglietti L, Dequidt C, Kamieniarz K, Rousset MC, Valnegri P, Thoumine O, Beretta F, Fagni L, Choquet D, Sala C, Sheng M, Passafaro M (2007) Extracellular interactions between GluR2 and N-cadherin in spine regulation. Neuron 54:461-477.

Suter DM, Forscher P (1998) An emerging link between cytoskeletal dynamics and cell adhesion molecules in growth cone guidance. Curr Opin Neurobiol 8:106-116.

Suter DM, Errante LD, Belotserkovsky V, Forscher P (1998) The Ig superfamily cell adhesion molecule, apCAM, mediates growth cone steering by substrate-cytoskeletal coupling. J Cell Biol 141:227-240.

Thoumine O, Meister JJ (2000) A probabilistic model for ligandcytoskeleton transmembrane adhesion: predicting the behavior of microspheres on the surface of migrating cells. J Theor Biol 204:381-392.

Thoumine O, Saint-Michel E, Dequidt C, Falk J, Rudge R, Galli T, FaivreSarrailh C, Choquet D (2005) Weak effect of membrane diffusion on the rate of receptor accumulation at adhesive contacts. Biophys J 89:L40-L42.

Thoumine O, Lambert M, Mege RM, Choquet D (2006) Regulation of $\mathrm{N}$-cadherin dynamics at neuronal contacts by ligand binding and cytoskeletal coupling. Mol Biol Cell 17:862-875.

Togashi H, Abe K, Mizoguchi A, Takaoka K, Chisaka O, Takeichi M (2002) Cadherin regulates dendritic spine morphogenesis. Neuron 35:77-89.

Yamada S, Pokutta S, Drees F, Weis WI, Nelson WJ (2005) Deconstructing the cadherin-catenin-actin complex. Cell 123:889-901.

Yap AS, Niessen CM, Gumbiner BM (1998) The juxtamembrane region of the cadherin cytoplasmic tail supports lateral clustering, adhesive strengthening, and interaction with p120ctn. J Cell Biol 141:779-789.

Yu X, Malenka RC (2003) Beta-catenin is critical for dendritic morphogenesis. Nat Neurosci 6:1169-1177. 